\title{
Refinement and validation of the Simple Lateral Mechanism Analysis (SLaMA) procedure for RC frames
}

Roberto Gentile ${ }^{\mathrm{a}^{*}}$, Ciro Del Vecchio ${ }^{\mathrm{b}}$, Stefano Pampanin ${ }^{\mathrm{c}}$, Domenico Raffaele ${ }^{\mathrm{d}}$, Giuseppina $\mathrm{Uva}^{\mathrm{ad}}$

a) Institute for Risk and Disaster Reduction, University College London, London, UK

b) Department of Structures for Engineering and Architecture, University of Napoli Federico II, Napoli, Italy

c) Department of Structural and Geotechnical Engineering, University of Rome "La Sapienza", Rome, Italy (Full professor); Department of Civil and Natural Resources Engineering, University of Canterbury, Christchurch, New Zealand (Adjunct professor)

d) Department of Civil, Environmental and Landscape, Building Engineering and Chemistry, Polytechnic University of Bari, Bari, Italy

*corresponding author. Email: r.gentile@ucl.ac.uk 


\title{
Refinement and Validation of the Simple Lateral Mechanism Analysis (SLaMA) procedure for $\mathrm{RC}$ frames
}

\begin{abstract}
The 2017 New Zealand Society for Earthquake Engineering (NZSEE) guidelines for seismic assessment of buildings recommends using SLaMA before implementing numerical analyses. The method and the NZSEE guidelines have been enhanced from the 2006 version, resulting into an efficient procedure, balancing simplicity and accuracy.

This paper presents a numerical study, initiated as part of the development of the SLaMA-2017 method, to investigate the accuracy of the analytical approach via comparison with numerical 2D-pushover on $40 \mathrm{RC}$ frames. SLaMA is effective in capturing the plastic mechanism of the frames, including global or soft-storey mechanisms. Further-yet-simple refinements of the procedure are suggested.
\end{abstract}

Keywords: Seismic assessment; Displacement-Based Assessment; reinforced concrete; existing buildings; non-linear analysis.

\section{Introduction}

Several difficulties arise in the seismic assessment of existing buildings, as the lack of capacity design principles and adequate reinforcement details, amongst many other "deficiencies", strongly affect the structural response. Nowadays, it is widely recognised that non-linear analyses, rather than linear approaches, are arguably the most reliable tool to characterise the lateral capacity of existing structures. Although they are available in user-friendly commercial software, their reliability and accuracy strongly depend on the ability of the numerical model to capture the probable failure mechanism, which in turns depends on the lateral capacity, both in terms of forces/moments and displacements/rotations, of the main structural members and their mutual interaction. These aspects are difficult to capture and can lead to high uncertainties in the seismic response. Reliable yet simple assessment procedures are needed to identify potential structural weaknesses and their influence on the overall building capacity.

In the scientific literature, efforts were made in developing analytical non-linear procedures such as [Borzi et al., 2008, Crowley et al., 2004, Cardone and Flora, 2017]. The Simple Lateral Mechanism Analysis (SLaMA) is an analytical - basically "by hand"- thus implementable within a 
spreadsheet - method that allows to define the non-linear force-displacement capacity and the sequence of local and global mechanisms of a building system by using simple calculations. It was introduced for the first time in the 2006 version of the New Zealand Society of Earthquake Engineering, NZSEE, Guidelines for the "Assessment and Improvement of the Performance of buildings in earthquakes" [NZSEE 2006], and significantly revamped in the 2017 version [NZSEE 2017]. The procedure originates from a pioneering capacity design-based assessment procedure [Priestley and Calvi, 1991], later converted in a displacement-based assessment procedure by Priestley [1997]. This constitutes the basis of the procedure proposed in the NZSEE [2006] guidelines, along with the capacity models for RC members reported in Priestley et al. [2007] and Pampanin et al. [2007]. In the NZSEE [2017] guidelines "The Seismic Assessment of Existing Buildings", a significantly revised and enhanced version of the SLaMA procedure has been introduced as part of the Detailed Seismic Assessment (DSA). The application of SLaMA is required as an essential step before any other seismic numerical analysis is carried out.

A full example of the detailed implementation of the SLaMA procedure for a 3D, torsionprone RC case study building, damaged during the Canterbury Earthquake on 22 February 2011, along with a comparison with numerical non-linear analyses (2D pushover, 3D time history) is reported in Del Vecchio et al., [2017a,2018b]. Further research focused on the use of SLaMA as a tool to validate more sophisticated numerical models [Gentile et al., 2017a], or to rapidly develop fragility curves for RC frame buildings [Gentile et al., 2017b].

The significant effort in collecting, developing and simplifying the available procedures and the capacity models for existing RC structures resulted in the NZSEE 2017 version of the SLaMA. However, several issues still need to be addressed.

This paper presents the validation of the SLaMA procedure for RC bare frames, individuating the existing gaps and proposing refinements accordingly. In particular, a more refined estimation of the effective height for different plastic mechanisms is given, which also allows to estimate the 
displacement profile of the frame. Moreover, a new set of equations is given for Column-Sway (softstorey) mechanisms, which is valid for soft-storey mechanisms located at any storey of the frame.

An extensive parametric analysis over 40 case study frames with different geometry and mechanical properties is presented. The analytical capacity curves, the plastic mechanisms and the relevant parameters for the seismic assessment are calculated and compared with the results of refined numerical pushover analyses. Both the original and the refined versions of SLaMA are considered. The comparison outlines the ability of SLaMA to capture the capacity curve and plastic mechanism of the frames (global or soft-storey). The limitations of the procedure are discussed and suggestions for further researches are given. In particular, it is acknowledged that RC frames usually interact with infill walls. This may significantly affect the lateral response of the structural system resulting in significant increase of the lateral stiffness, higher seismic forces and possible brittle failures both in the structural and non-structural members [Magenes and Pampanin, 2004]. Although such interaction is of great interest, it is outside the scope of this paper and further research is needed.

\section{Overview of the SLaMA 2017 procedure for RC frames and proposed refinements}

SLaMA is an analytical procedure that allows to assess the non-linear capacity (force vs deformation) and the plastic mechanism of a structural system starting from the capacity of the primary structural members/systems [NZSEE 2017]. Since it relies on basic principles (i.e. equilibrium and compatibility), SLaMA is referred to as a "by hand analytical pushover analysis" since all the calculations can be easily implemented in a spreadsheet. Given the "deficiencies" of existing buildings (e.g. lack of capacity design, inadequate joint panel reinforcement), there is a need for practical implementation tools to test the reliability of numerical models in predicting the plastic mechanism. SLaMA aims to address this need, together with supporting the selection of retrofit strategies/techniques at earlier stages of the assessment process.

With reference to RC bare frames, a proposed flowchart of the SLaMA procedure is depicted in Figure 1. The NZSEE [2017] SLaMA procedure is therefore described on a step-by-step basis, 
highlighting the proposed refinements.

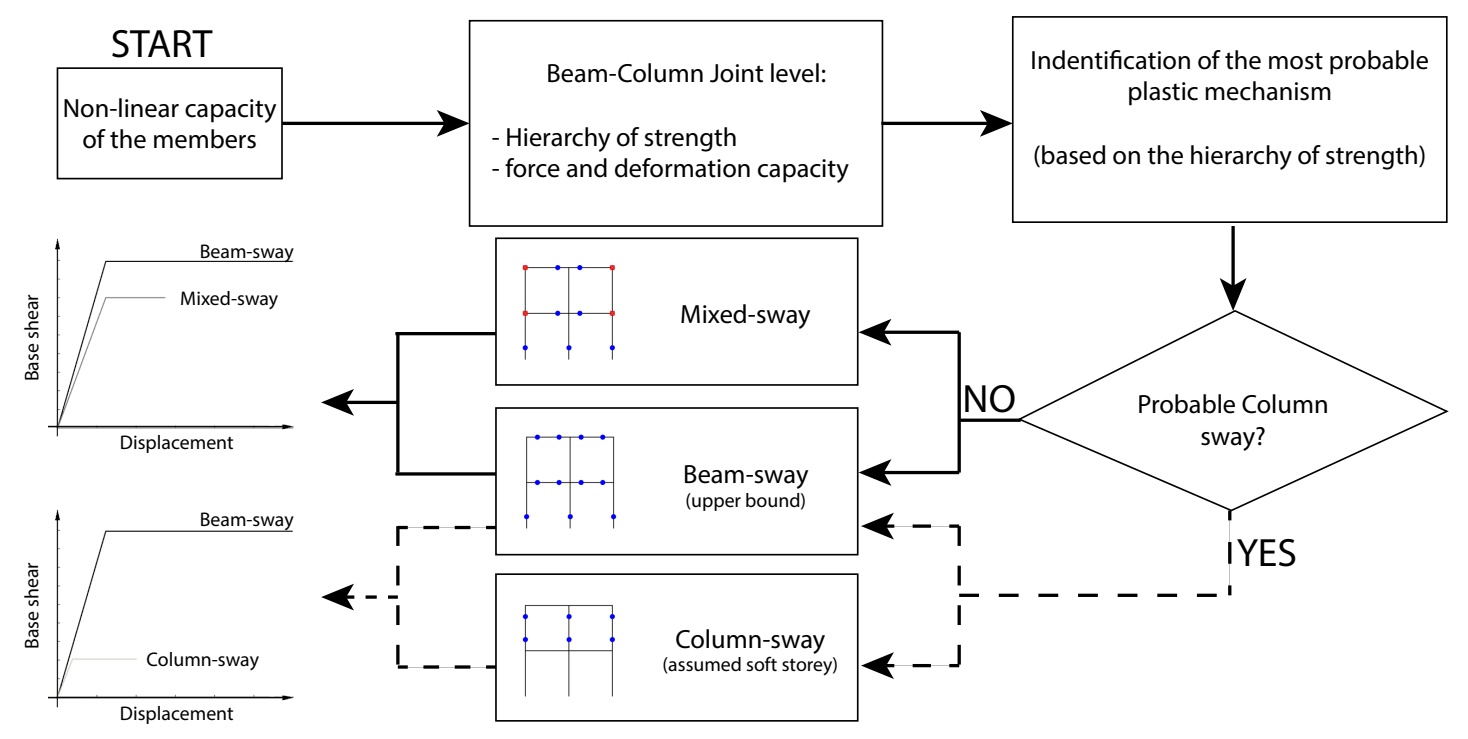

Figure 1 Proposed flowchart for the refined SLaMA procedure.

The first step of the SLaMA is the characterisation of the lateral response of the main structural members (i.e. beams, columns, beam-column joints) composing the frame. The interaction between the members in the beam-column joint sub-assemblies is studied using the hierarchy of strength principle [Pampanin et al., 2007]. Once the failure mode of the sub-assembly is detected, its strength and deformation capacity are assessed using equilibrium considerations. It is proposed to use the results of the hierarchy of strength for all the sub-assemblies to identify the probable plastic mechanism of the frame. Sets of equations are given to calculate the capacity curve for three recurrent plastic mechanisms. A "Column-Sway" (soft-storey), with plastic hinges at the top and the bottom of all the columns of a given storey, a "Beam-Sway", global mechanism characterised by plastic hinges at the end of all the beams, and a "Mixed-Sway", in which a combination of beam, column and/or joint failures can be triggered.

If a Column-Sway is likely to develop (which is likely to be the lower bound of the capacity for pre-1970s buildings designed without proper capacity design considerations), the related capacity curve is calculated. Otherwise, the Mixed-Sway case is more likely to develop, and the related capacity curve is calculated. In both cases, a "Beam-Sway" capacity curve is also calculated. This 
gives a measure of the upper bound of the force/displacement capacity, since this refers to the highest capacity a frame can develop. This might be the case of well-designed RC frames in compliance with capacity design principles or the target for an optimal retrofit intervention for the frame.

For the described SLaMA procedure, the following assumptions hold:

- first vibration mode response dominates the behaviour of the Lateral Resisting System;

- floor slabs are rigid in plane, acting as a diaphragm. This is a reasonable assumption for cast in-situ flat slabs;

- the columns are fully fixed at the base;

- for global mechanisms (Beam-Sway or Mixed-Sway), it is assumed that all the beam-column joint sub-assemblies in the frame can exploit their maximum strength capacity, (determined according to the hierarchy of strength);

- the frame strength is calculated based on the expected plastic mechanism;

- any hardening of the structural members is conservatively neglected in the calculation of the global base shear, hence the global base shear at yielding and ultimate are equal. Conversely, member hardening is considered in the calculation of the hierarchy of strength calculation, since it may greatly affect such a prediction.

\subsection{Members capacity curves}

The lateral response and the most probable failure mechanism of the structural members (i.e. beams, column and beam-column joints) should be assessed using reliable capacity models. In this section, the capacity models suggested in NZSEE 2017 are summarised while a detailed description and the step-by-step calculations for existing RC members are reported in Gentile, 2017 and Del Vecchio et al., $[2017 \mathrm{a}]$.

The flexural capacity of the RC members can be derived using reliable numerical or analytical procedures and including the effect of the axial load. Then, the flange effect [Quintana-Gallo, 2014, NZSEE 2017], lap splice failure [Priestley et al., 1996], shear failure [Kowalsky and Priestley, 2000, 
Elwood and Moehle, 2005, Del Vecchio et al., 2017c], bar buckling [Berry and Eberhard, 2005] should be considered, as they can significantly modify the lateral response of the members (Table ). Table 1 Capacity models for the characterisation of the members.

Bar buckling drift [Berry and Eberhard, 2005]

Shear strength for beams and columns [Kowalsky and Priestley, 2000]

Ultimate displacement for flexureshear failure [Elwood and Moehle 2005]

where: $\rho_{s}, f_{y h}$ volumetric ratio and yield stress of the transverse reinforcement; $k_{e_{-} b b}$ transverse reinforcement coefficient; $\rho_{e f f}$ effective confinement ratio; $d_{b}$ average diameter of longitudinal reinforcement; $D$ section effective depth; $P$ member axial load; $A_{g}$ gross section area; $f_{c}^{\prime}$ unconfined concrete strength; $L_{v}$ shear span; $\alpha, \beta, \gamma$ aspect ratio, dowel effect and shear strength degradation factors; $b_{w}$ width of section web; $d$ effective depth of section; $s$ stirrup spacing; $v$ shear stress ratio.

The principal stress approach, combining joint shear and gravity load, is adopted to calculate the horizontal joint shear strength $\left(V_{j h}\right)$. Figure 2 shows the experimentally-validated limits for the principal tensile/compressive stress $\left(p_{t}, p_{c}\right)$ used for the calibration of the joints [Priestley 1997, Pampanin et al., 2003, NZSEE 2017]. It is worth mentioning that the selected values for the joint ultimate drift ( $1 \%$ for exterior, $1.5 \%$ for interior) are equal to the drift for which the onset of strength degradation was experimentally observed (Pampanin et al., 2003, Del Vecchio et al. 2018a). Therefore, joint strength degradation has been neglected in this study resulting in conservative estimations of the ultimate displacement capacity of the frame."

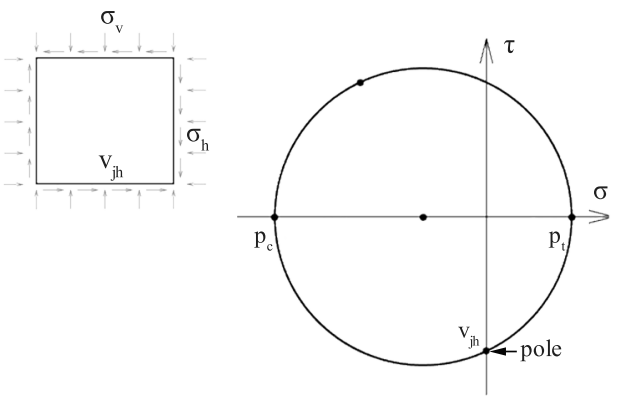

a) Mohr's circle for the joint panel

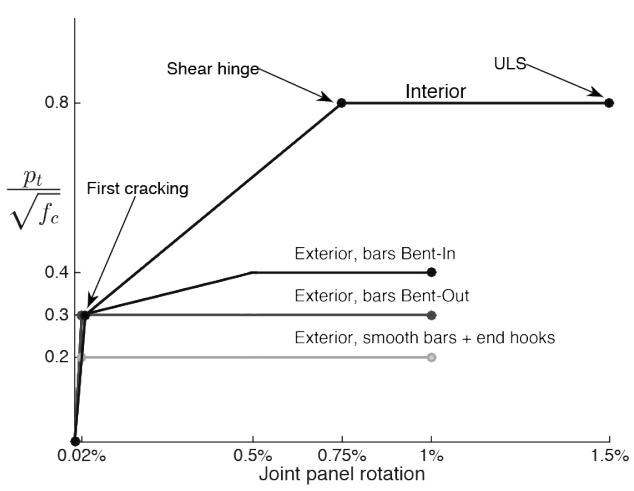

b) Typical principal tensile stress vs panel rotation

Figure 2 Typical joint capacity curves for different detailing.

\subsection{Strength and deformation capacity of beam-column joint sub-assemblies}

The global performance of a frame structure can be assessed by characterising the performance of the 
beam-column joint sub-assemblies, i.e. the portion of the frame enclosed by the contra-flexure points of beams and columns (assumed at mid span). If the failure mechanism of the weakest member in the sub-assembly allows hardening, hence further increase of the lateral force, another mechanism may activate. For example, the first shear cracking of the joint panel allows the increase in the external force until, for instance, a beam hinge may develop (see Figure 3.c).

As suggested in Calvi et al., [2002] and Pampanin et al., [2007], to compare different members and failure modes the Equivalent Column Moment $(E C M)$ is used. This is the moment in the column, calculated at the joint interface, corresponding to a given member failure mechanism in the subassembly. By means of equilibrium conditions at sub-assembly level (Figure 3), this is calculated for each member failure mechanism and plotted in an Equivalent Column Moment-axial load performance domain (Figure 3.c, related to an exterior sub-assembly). For instance, the Equivalent Column Moment corresponding to the yield moment of the beam (which does not vary with the column axial load) corresponds to a horizontal line in the performance domain.

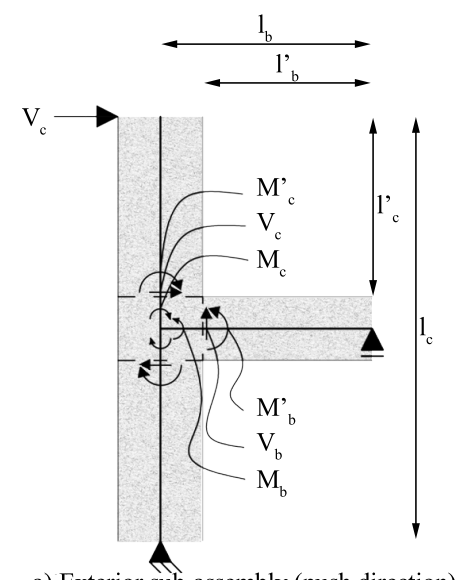

a) Exterior sub-assembly (push direction)

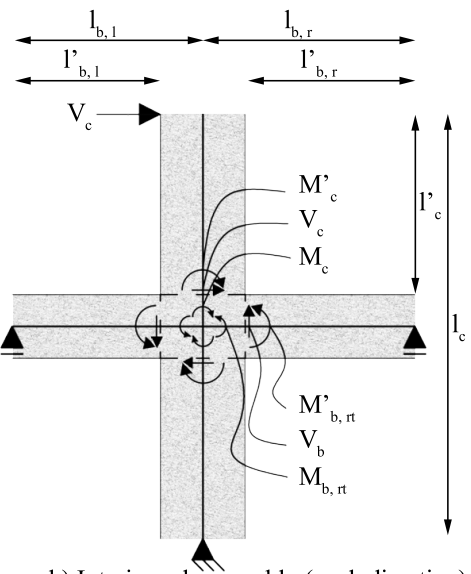

b) Interior sub-assembly (push direction)

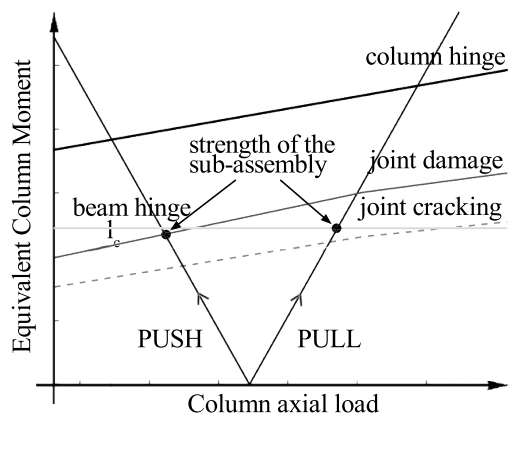

c) performance domain (exterior sub-assembly)

Figure 3 Sub-assemblies: rotational equilibrium about the joint centroid.

The seismic demand on the sub-assembly due to the lateral sway of the frame is defined in the M-N domain by two straight lines anchored in the point corresponding to zero-moment and gravity axial load. Considering both directions of the seismic action, the demand appears as a V-shaped curve. The slope of the lines corresponds to the ratio of the seismic moment to seismic axial load on the column $\left(M_{E} / N_{E}\right)$. Details on this calculation are given in Gentile [2017] and Del Vecchio et al. [2017a]. 
The formulations for the Equivalent Column Moment are summarised in Table 2 (see also Figure 3). Some modifications are made with respect to NZSEE 2017 to account for the different lengths for the left and right beams in interior sub-assemblies. Besides, this refinement allows for the accurate determination of the hierarchy of strength if the yielding moment of left and right beams vary significantly. It is worth mentioning that for interior and exterior roof sub-assemblies, the same formulations can be used, provided that the net column length $\left(l_{c}^{\prime}\right)$ is divided by two.

Table 2 Equivalent Column Moment for interior and exterior sub-assemblies.

\begin{tabular}{|c|c|c|}
\hline Mechanism & $\begin{array}{l}\text { Eq. Col. Moment } \\
\text { (ext. sub-assembly) }\end{array}$ & $\begin{array}{l}\text { Eq. Col. Moment } \\
\text { (int. sub-assembly) }\end{array}$ \\
\hline Column hinge (top or bottom) & $M_{c y}^{\prime}$ & $M_{c y}^{\prime}$ \\
\hline Column Shear (top or bottom) & $l_{c}^{\prime} V_{c}$ & $l_{c}^{\prime} V_{c}$ \\
\hline \multirow[t]{2}{*}{ Beam hinge } & $\frac{l_{c}^{\prime} l_{b}}{l_{c} l_{b}^{\prime}} M_{b y}^{\prime}$ & $\frac{l_{c}^{\prime}}{l_{c}}\left(\frac{l_{b, l}}{l_{b, l}^{\prime}}+\frac{l_{b, r}}{l_{b, r}^{\prime}}\right) M_{b y, l}^{\prime} \quad(*)$ \\
\hline & & $\frac{l_{c}^{\prime}}{l_{c}}\left(\frac{l_{b, l}}{l_{b, l}^{\prime}} M_{b y, l}^{\prime}+\frac{l_{b, r}}{l_{b, r}^{\prime}} M_{b y, r}^{\prime}\right)(* *)$ \\
\hline Beam Shear & $V_{b} l_{b} \frac{l_{c}^{\prime}}{l_{c}}$ & $V_{b}\left(l_{b, l}+l_{b, r}\right) \frac{l_{c}^{\prime}}{l_{c}}$ \\
\hline \multirow[t]{2}{*}{ Joint } & $V_{j h} l_{c}^{\prime}$ & $V_{j h} l_{c}^{\prime}$ \\
\hline & $\overline{\frac{l_{c} l_{b}^{\prime}}{l_{b} j d}-1}$ & $\frac{2 l_{c}}{j d\left(\frac{l_{b, l}}{l_{b, l}^{\prime}}+\frac{l_{b, r}}{l_{b, r}^{\prime}}\right)}-1$ \\
\hline
\end{tabular}

where $l_{c}$ is the distance between two contra-flexure points on the columns; $l_{c}^{\prime}$ is the shear span of the column, $l_{b, l}$ is the distance between the joint centroid and the left beam mid-span, $l_{b, r}^{\prime}$ is the shear span of the right beam, $M_{c y}^{\prime}$ is the yield moment of the top (or bottom) column calculated at the joint interface, $M^{\prime}{ }_{b y, l}$ is the yield moment of the beam calculated at the joint interface, $V_{b}$ is the beam shear capacity (left or right), $V_{c}$ is the column shear capacity (top or bottom), $V_{j h}$ is the joint shear capacity (at first cracking or failure), jd is the internal lever arm of the beam.

(*) It is assumed that only one beam yields. The right beam yielding moment should be used if $M_{b y, r}<M_{b y, l}$

$(* *)$ It is assumed that both beams yield.

The strength of a sub-assembly $\left(M_{c}^{* \prime}\right.$; the symbol ' indicates that this is computed at the column/joint interface) depends on the first mechanism in the hierarchy of strength that does not allow any further increase in the external forces. With reference to the performance domain in Figure 3.c, in the "push" direction (corresponding to a decreasing axial load on the column) the first cracking of the joint is likely to develop first. If deformed beam bars are bent into the joint panel, the shear force can further increase (see Figure 2) and the next mechanism (joint failure) can be triggered. Therefore, in the "push" direction, the strength of the sub-assembly is characterised by the ECM corresponding to the 
joint failure. In the "pull" direction (corresponding to an increasing axial load on the column), the beam yields after the joint first cracking. Beam hardening allows for further increases in the external forces, but this is not sufficient to activate the next mechanism. Therefore, the strength of the subassembly is related to the ECM corresponding to the beam flexural yielding.

Once the ECM corresponding to the strength of the sub-assembly is calculated $\left(M_{c}^{* \prime}\right)$, the related Equivalent Beam Moment $\left(M_{b}^{*}\right)$ can be computed with Eq. 1, imposing rotational equilibrium about the joint centroid (see Figure 3) and assuming that the beam moment is equally-distributed in the top and bottom columns. $n_{\text {cols }}$ and $n_{\text {beams }}$ represent the number of columns and beams framing in a joint.

$$
\begin{gathered}
M_{b}^{*}=\frac{n_{\text {cols }} M_{c}^{*}}{n_{\text {beams }}} \text {, where: } \\
M_{c}^{*}=\frac{l_{c}}{l_{c}^{\prime}} M_{c}^{* \prime}
\end{gathered}
$$

Many experimental tests on sub-assemblies [Pampanin et al., 2002, Calvi et al., 2002, Del Vecchio et al., 2016] demonstrated that the beams, the columns and the joint panel contribute to the total drift. However, most of the inelastic deformation is concentrated in the weakest member, whose drift is used to determine the drift capacity of the sub-assembly. For this example, the yield $\left(\theta_{\text {sub } y}\right)$ and ultimate $\left(\theta_{\text {subu } u}\right)$ drifts of the sub-assembly, in the "push" direction, are equal to the joint panel drift limits corresponding to the joint cracking and the joint shear failure, respectively. In the "pull" direction, the beam yielding and ultimate drift govern the deformation of the sub-assembly.

\subsection{Plastic mechanism and definition of the capacity curve}

The probable plastic mechanism of the frame is assessed based on the hierarchy of strength of all the sub-assemblies that compose the frame. Figure 4.a indicates a "Beam-Sway" mechanism, in which plastic hinges develop in all the beams at all the storeys, along with the flexural yielding of the base columns. If any joint shear failures, column plastic hinges (except from the base), shear failures in beams and/or columns or lap-splice failures is predicted, the plastic mechanism is called "Mixed- 
Sway" (Figure 4.b). Finally, if the hierarchy of strength leads to a soft-storey behaviour, as for Figure 4.c, the mechanism is a "Column-Sway". For asymmetric frames, either in geometry or in the strength of the members, the same process should be repeated using the hierarchy of strength in the "pull" direction, checking for major changes in the result, and possibly calculating two different capacity curves.
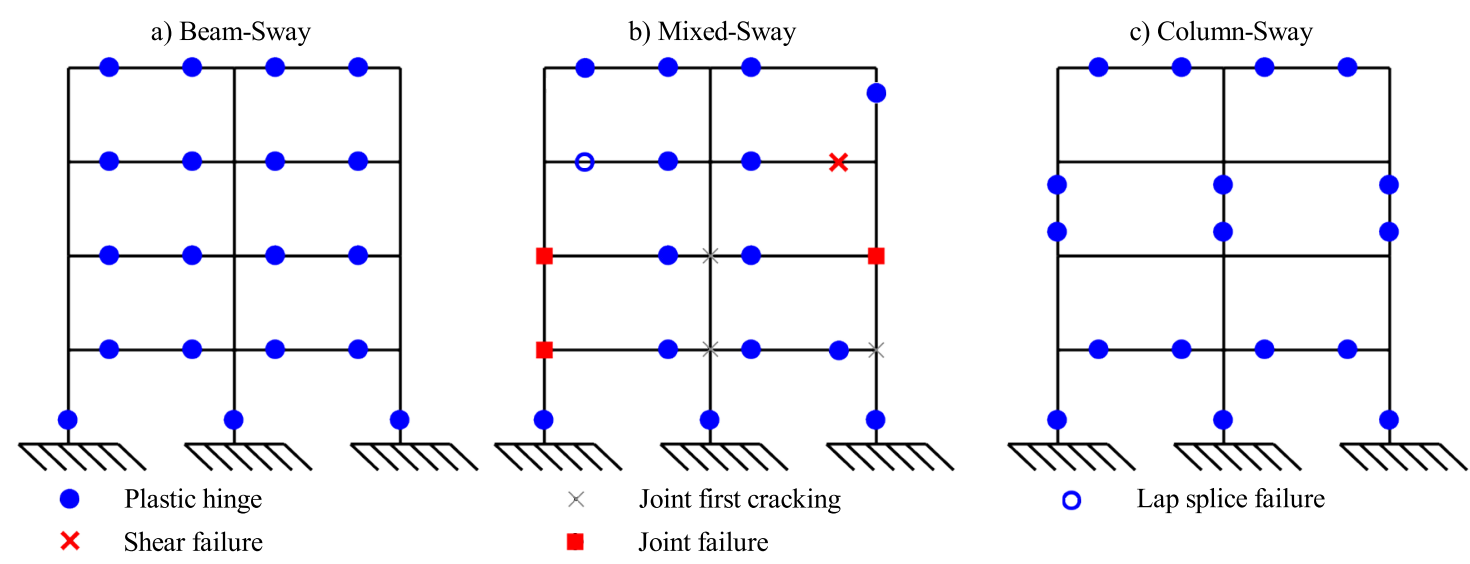

Figure 4 Examples of hierarchy of strength resumes for 2-bays, 4-storeys frames (push direction, external forces from pointing right).

As a general approach, the bi-linear representation of the frame capacity curve is calculated using global equilibrium and by considering the member(s) causing yielding and the ultimate limit state. An approximate displacement shape is assumed. Different formulations to derive the frame base shear are available for each plastic mechanism type (i.e. Beam-Sway, Mixed-Sway and Column-Sway).

\subsubsection{Beam-Sway mechanism}

According to the NZSEE [2017] procedure, unchanged herein, the overturning moment $($ OTM $=$ $\sum F_{i} H_{i}$, where $H_{i}$ is the height of the $i^{t h}$ storey from the foundations) resisted by the structure at ULS can be calculated with Eq. 3 , in which $j$ is the considered joint and $i$ indicates the storey, $M_{c y}$ is the column yielding moment, $M_{b y, l}$ and $M_{b y, r}$ are the left and right beam yielding moments and $L_{\text {bay }}^{\text {ext }}$ is the length of the external bay. For regular frames with the beams at the same storey that have the same moment capacity, only the moments on the external beams are used. An extended procedure 
valid for irregular frames can be found in [Priestley et al., 2007]. The base shear capacity of the frame is obtained dividing the OTM by the effective height of the frame in a Beam Sway configuration $\left(H_{e f f}^{B S}\right.$, Eq. 4). The effective height is calculated with Eq. 5, using the ultimate displacement profile $\Delta_{i}^{u}$ (calculated as shown below in this section). P-Delta effects might be considered subtracting the second order overturning moment $\left(O T M^{P \Delta}\right)$ to the first order capacity. For the ultimate point of the capacity curve, Eq. 6 can be used, where $P_{i}$ is the sum of the vertical gravity loads at storey $i$. A linear interpolation should be considered between the origin and the ultimate condition. It is worth mentioning that this aspect is outside the scope of this paper and needs further validation

$$
\begin{gathered}
\text { OTM }^{B S}=\sum_{j} M_{c y j}+\sum_{i} \frac{M_{b y, l i}+M_{b y, r i}}{L_{b a y}^{\text {ext }}} L \\
V_{B}^{B S}=\frac{O T M^{B S}}{H_{\text {eff }}^{B S}} \\
H_{e f f}^{B S}=\frac{\sum_{i} m_{i} \Delta_{i}^{u} H_{i}}{\sum_{i} m_{i} \Delta_{i}^{u}} \\
\text { OTM } M^{P \Delta}=\sum_{i} P_{i} \Delta_{i}^{u}
\end{gathered}
$$

Each sub-assembly is characterised by the yield $\left(\theta_{\text {sub } y}\right)$ and ultimate $\left(\theta_{\text {sub } u}\right)$ drift capacity. For a Beam-Sway mechanism these are equal to the beam yield and ultimate drift, respectively. According to the SLaMA procedure proposed in the NZSEE [2017], the yielding and ultimate displacement of the frame at the effective height can be computed as the product of the effective height and the minimum yielding or ultimate drift of the beams, respectively. Although this is a very simple method, this is a clear approximation, since it does not capture the dependency of the effective height on the number of storeys. Indeed, a fixed value equal two-thirds of the total height is suggested in NZSEE [2017].

In the refined formulation proposed in this work, it is assumed that the displacement shape of the frame $\left(\delta_{i}\right)$ is governed by Eq. 7, proposed by Priestley et al. [2007], in which $H_{n}$ is the total height. This results in a unitary displacement at the top (dashed line in Figure 5.c). The original formula by 
Priestley et al. [2007] assumes a linear displacement shape for frames with four storeys or less and a non-linear shape otherwise. Based on the parametric analysis in this work, it is suggested to reduce this threshold to 2, for applications within the SLaMA framework. The related drift shape can be calculated as $\vartheta=\left(\delta_{i}-\delta_{i-1}\right) /\left(H_{i}-H_{i-1}\right)$, corresponding to the dashed line in Figure 5.b. The adjacent storey below the sub-assembly with the minimum yielding ultimate drift is named level $k$ (highlighted with a circle in Figure 5.a). If two or more sub-assemblies have the same yield or ultimate drift, level $k$ is the lowest. It may happen that level $k$ for the ULS is not equal to level $k$ for the yielding. The displacement profile (continuous line in Figure 5.c) at yielding $\left(\Delta_{i}^{y}\right)$ or ULS $\left(\Delta_{i}^{u}\right)$ can be computed by scaling the displacement shape $\left(\delta_{i}\right)$ by the factor min $\left(\theta_{\text {sub } y / u}\right) / \vartheta_{k}$. This procedure is graphically shown in Figure 5.

It is worth mentioning that the calculation of the frame yielding and ULS based on the minimum drift capacity of the sub-assemblies is simple but approximate, since the evolution of the internal actions over the frame is not accounted for.

$$
\delta_{i}=\left\{\begin{array}{cc}
\frac{H_{i}}{H_{n}} & \text { for } n \leq 2 \\
\frac{4}{3}\left(\frac{H_{i}}{H_{n}}\right)\left(1-\frac{H_{i}}{4 H_{n}}\right) & \text { for } n>2
\end{array}\right.
$$

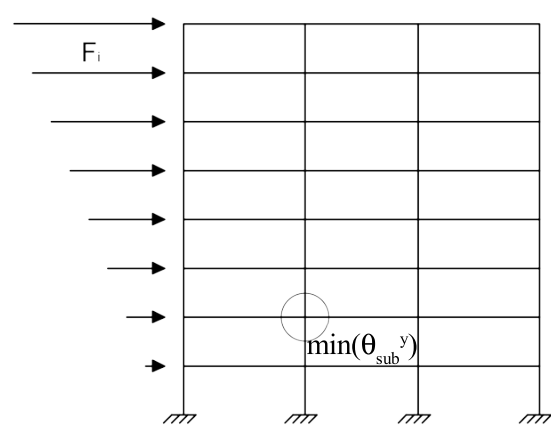

a) Individuation level $\mathrm{k}$

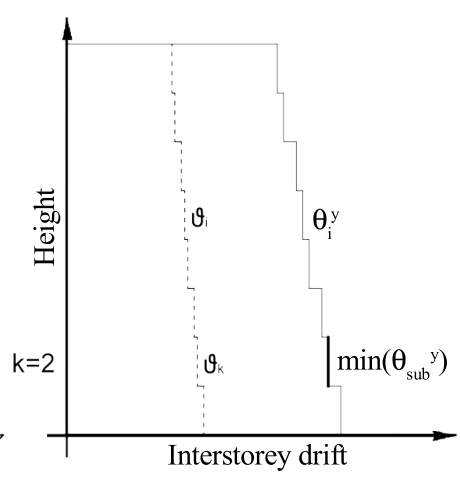

b) Drift calculation

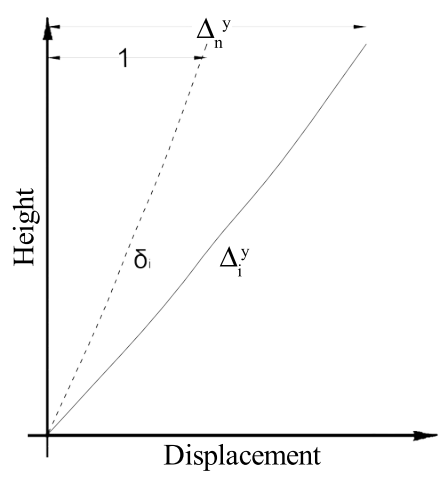

c) Displacement calculation

Figure 5 Calculation of the displacement profile at the yielding of the frame.

Finally, the displacement (at yielding and ultimate) at the effective height is calculated with Eq. 8, as proposed in Priestley et al., [2007]. 


$$
\Delta^{y / u}\left(H_{e f f}^{B S}\right)=\frac{\sum_{i} m_{i} \Delta_{i}^{y / u^{2}}}{\sum_{i} m_{i} \Delta_{i}}
$$

Typically, the Beam-Sway mechanism is not likely to characterise the response of existing RC frames. However, this capacity curve is the upper bound of the frame lateral capacity and it can provide useful information to design a proper retrofit solution.

\subsubsection{Mixed-Sway mechanism}

The procedure for the calculation of the capacity curve related to a Mixed-Sway mechanism follows the steps explained for the Beam-Sway mechanism (Section 2.3.1). However, in this case the strength $\left(M_{b}^{*}\right)$ and deformation $\left(\theta_{\text {sub } y / u}\right)$ capacity of the sub-assemblies are defined according to the refined hierarchy of strength (Section 2.2).

The displacement shape $\left(\delta_{i}\right)$ is calculated with Eq. 7 and then amplified by the ratio $\min \left(\theta_{\text {sub } y / u}\right) / \vartheta_{k}$, where $\vartheta_{k}$ is the drift shape at level $\mathrm{k}$ (see Section 2.3.1). The displacement at the effective height at yielding and ULS is calculated with Eq. 8. The overturning moment capacity $\left(O T M^{M S}\right)$ is calculated with Eq. 9. It differs from Eq. 3 since the moment corresponding to the failure is considered for the columns $\left(M_{c j}\right.$, i.e. flexure, shear or lap-splice $)$ instead of the yielding. The Equivalent Beam Moment (Section 2.2) at the left $\left(M_{b, l i}^{*}\right)$ and right $\left(M_{b, r i}^{*}\right)$ ends of the external beams at all storeys is used for this calculation. It is worth mentioning that, even for regular and symmetric frames, the Mixed-Sway OTM calculated using the left or right external beams can vary significantly. Hence, a mean value should be considered. After calculating the effective height with Eq. 5, the base shear capacity for the Mixed-Sway $\left(V_{B}^{M S}\right)$ is calculated dividing the OTM capacity by the effective height.

$$
O T M^{M S}=\sum_{j} M_{c j}+\sum_{i} \frac{M_{b, l i}^{*}+M_{b, r i}^{*}}{L_{b a y}^{e x t}} L
$$

If the ULS of the frame is conditioned by a brittle failure mode of one or more members, e.g. the shear failure in a column, yielding might be prevented. The ultimate displacement might be used to 
"trim" the first branch of the capacity curve and hence obtain the ultimate base shear. However, the initial stiffness of the capacity curve is based on the formation of a plastic mechanism (secant-toyield stiffness) which is clearly inappropriate if a brittle behaviour is expected. For this reason, the process of "trimming" the capacity curve yields a major error and it is hence not suggested. An elastic force-based analysis, based on gross or cracked stiffness of the members, is suggested in such situation.

\subsubsection{Column-Sway mechanism}

If the hierarchy of strength calculations for all the sub-assemblies indicate that a soft-storey mechanism is likely to be triggered at level $s$ (see Figure 4.c), a procedure alternative procedure to the one suggested in NZSEE [2017] is proposed to calculate the frame capacity curve. It is worth mentioning that the Column-Sway procedure proposed in NZSEE [2017] is theoretically valid only for soft-storey mechanisms located at the first storey. Moreover, a constant effective height (50\% of the total height) is suggested, regardless of the number of storeys. The proposed procedure overcomes both issues. It can be employed independently of the location of the soft storey and it allows the calculation of both the displacement profile and the effective height. It is worth mentioning that if two or more storeys are "soft-storey prone", based on the hierarchy of strength, different ColumnSway capacity curves are calculated. The capacity curve with the lowest base shear is considered as the most probable.

The peak shear strength of the soft-storey level $s\left(V_{\text {int } s}\right)$ depends on the capacity of the columns at that storey $\left(M_{c}\right.$, depending on their predicted failure mode). It can be calculated with Eq. 10 , where $j$ is the generic column at level $s, h_{\text {int } s}$ is the inter-storey height of level $\mathrm{s}$ and $h_{b}^{\text {top }}$ and $h_{b}^{\text {bot }}$ are the average depths of the beams above and below storey $s$.

$$
V_{\text {int } s}=\frac{\sum_{j} M_{c j}^{t o p}+\sum_{j} M_{c j}^{b o t}}{h_{\text {int } s}-\frac{h_{b}^{t o p}}{2}-\frac{h_{b}^{b o t}}{2}}
$$


If in a first approximation it is assumed that the horizontal force profile is linear (Eq. 11), the shear demand for a unit base shear, $V_{B}=1$, can be calculated with Eq. 12. This assumption should be verified as shown below. As shown in Figure 6, the base shear strength of the frame can be estimated by scaling the shear demand at level $s$ related to the unit base shear $\left(V_{s}^{(1)}\right)$ matching the shear capacity at that storey $\left(V_{\text {int }}\right.$, see Eq. 13). P-Delta effects might be added calculating the second order OTM as per Section 2.3.1, dividing it by the effective height and subtracting this second order base shear to the first order base shear capacity.

$$
\begin{gathered}
F_{i}=\frac{m_{i} H_{i}}{\sum m_{i} H_{i}} V_{B} \\
V_{i}=\sum_{i}^{n} F_{i} \\
V_{B}^{C S}=\frac{V_{\text {int } s}}{V_{S}^{(1)}}\left(V_{1}^{(1)}=1\right)=\frac{V_{\text {int } s}}{V_{s}^{(1)}}
\end{gathered}
$$
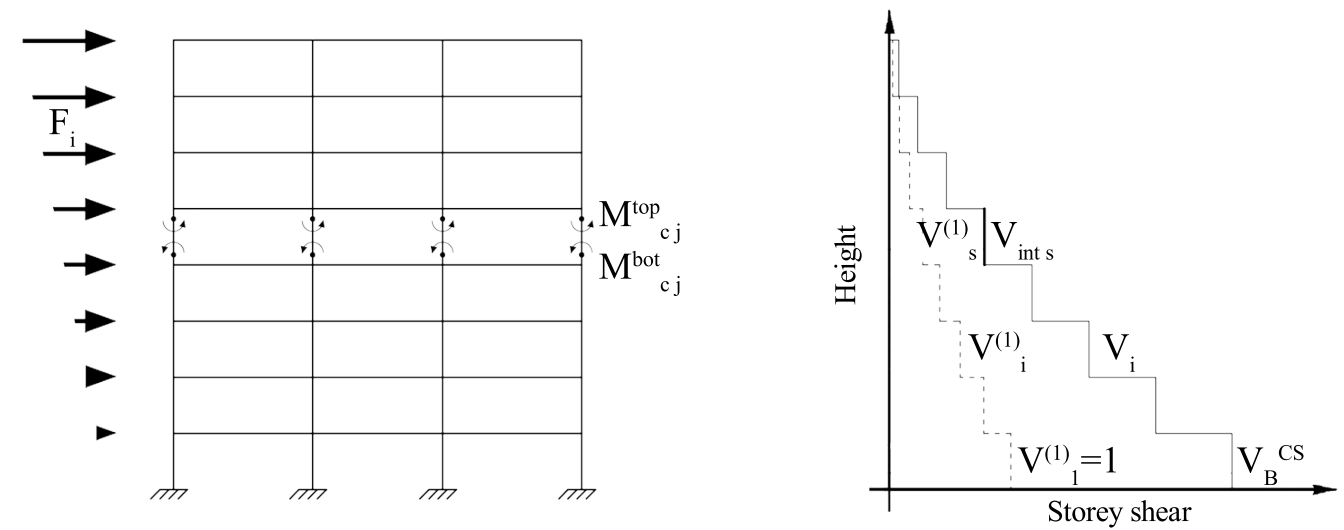

Figure 6 Assessment of the base shear capacity for a Column-Sway mechanism.

The yield drift at the soft-storey level, $\theta_{\text {sy }}$, is the minimum yield drift of the columns at that storey. To calculate the drift demand at the other storeys, the shear demand is divided by the secant-toyielding stiffness of each storey $K_{i}^{C S}$ (Eq. 14, which indicates the shear force that produces a unit inter-storey drift). The latter can be calculated using Eq. 15, in which $i$ represents the considered 
storey and $j$ represents a column at that storey.

$$
\begin{gathered}
\theta_{i}^{y}=\frac{V_{i}}{K_{i}^{C S}} \\
K_{i}^{C S}=\frac{\sum_{j} 12 E J_{s e c, j}}{h_{\text {int } i}^{2}}
\end{gathered}
$$

The "yielding" displacement profile $\Delta_{i}^{y}$ can be calculated recursively, starting from the drift of the first storey. Once a soft storey has developed, it is assumed that the plastic deformation concentrates only at level $s$. The plastic displacement profile $\Delta_{i}^{p}$ can be computed with Eq. 16 , where $\theta_{s u}$ is the minimum ultimate drift of the columns at level $s$. It is worth mentioning that two different columns can be responsible of the yield and ultimate drifts of level $s$. The yielding and plastic displacement are summed up to obtain the ultimate displacement profile $\Delta_{i}^{u}$ (Figure 7). Finally, the yield and ultimate displacement at the effective height are calculated with Eq. 8, while the effective height is calculated with Eq. 5 .

$$
\Delta_{i}^{p}=\left\{\begin{array}{cc}
0 & \text { for } i<s \\
\left(\theta_{s}^{u}-\theta_{s}^{y}\right) h_{\text {int } s} & \text { for } i \geq s
\end{array}\right.
$$

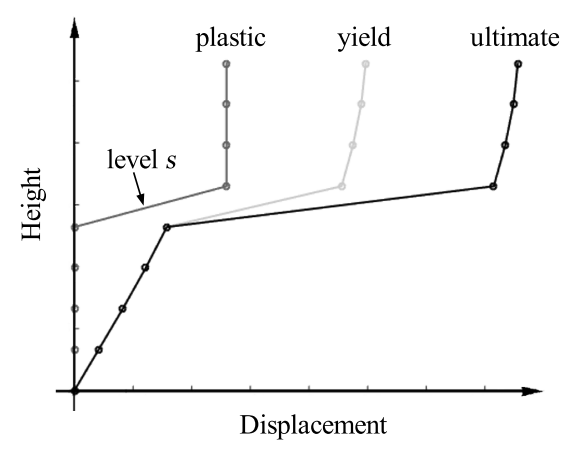

Figure 7 Displacement profile for a Column-Sway mechanism.

It is worth mentioning that a linear force profile might not be adequate to represent the post-yielding behaviour of a frame experiencing a soft-storey mechanism. Therefore, it is generally suggested to repeat the above-mentioned procedure by considering a uniform displacement profile (Eq. 17, where 
$\mathrm{n}$ is the number of storeys) to verify such assumption.

$$
F_{i}=\frac{1}{n} V_{B}
$$

\section{Numerical investigation on a set of prototype frame structures}

The SLaMA procedure, as originally proposed in NZSEE [2017] and in the refined version (without P-Delta effects), is herein applied to a set of case study frame structures. The non-linear capacity curves and the related displacement profile are compared with the results of refined numerical pushover analyses. The accuracy of SLaMA is assessed in terms of the SLaMA-to-numerical error for some key parameters (i.e. displacement at the effective height at yielding and ultimate conditions, related effective height and ultimate base shear).

A set of 40 case study frames is used in this work (Figure 8), including two- or four-bays frames with $2,4,6,8$ or 10 storeys. These frames are intended to be the longitudinal frames of the buildings depicted in Figure 8. It is worth mentioning that the assessment of the transverse frames is not considered in this paper. The contribution of the transverse frames (out-of-plane capacity) is neglected since it is significantly smaller than the in-plane capacity of the longitudinal ones. Internal columns, with negligible lateral load bearing capacity, are provided to resist gravity loads only. The layout of the structures is regular, with a bay length of $5.5 \mathrm{~m}$ and an inter-storey height of $3.3 \mathrm{~m}$. The database is divided into 4 sub-sets composed of 10 frames with 2 or 4 bays and 2, 4, 6, 8, 10 storeys. Each sub-set is characterised by frames with different failure mechanism (i.e. Beam-Sway, MixedSway, Column-Sway at the ground storey, Column-Sway at mid height, see Section 3.2). 


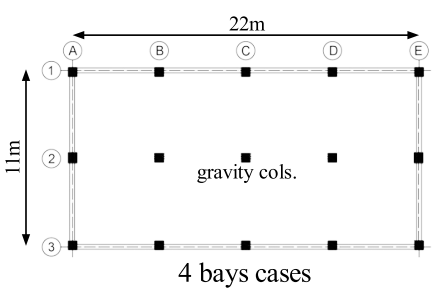

$\underline{\text { Plan view }}$
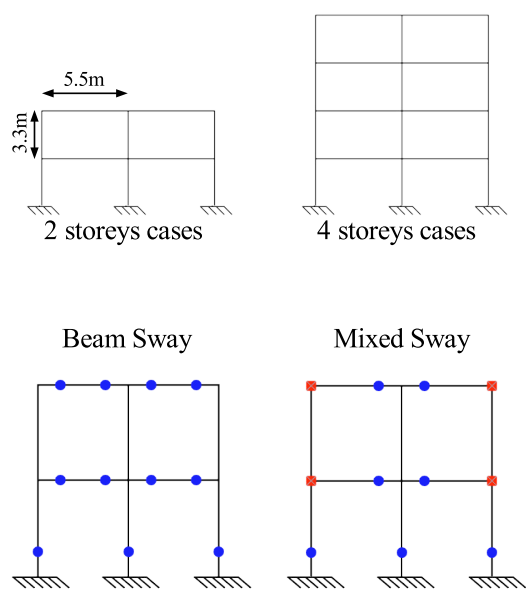
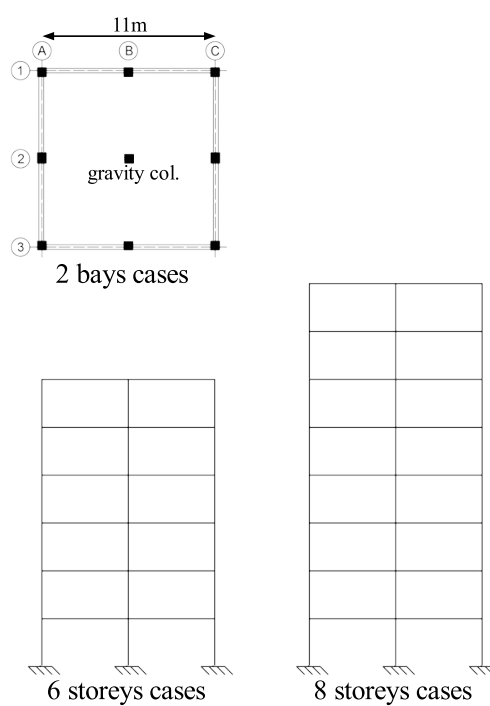

Elevation

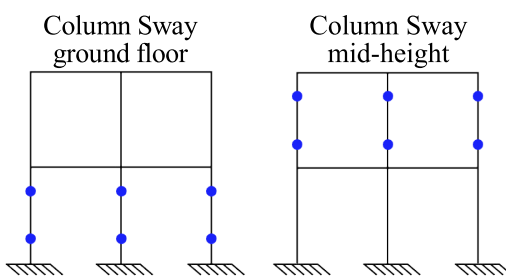

- Plastic Hinge

- Joint shear hinge

Joint cracking

Expected plastic mechanisms

Figure 8 Case study matrix for the parametric analysis.

\subsection{Materials properties and load analysis}

The material properties chosen for all the case studies are meant to be representative of the average values typical of existing RC structures (NZSEE 2017, appendices C5E.1- C5E.3). A concrete compressive strength equal to $f_{c}^{\prime}=25 \mathrm{MPa}$ is used, since it is typical of RC buildings built in the 70 s'$^{\prime} / 80 \mathrm{~s}^{\prime}$. For the mechanical characterisation of the structural members, concrete is modelled according to Mander et al., [1988], considering an elastic modulus equal to $E_{c=} 5000 \sqrt{f_{c}^{\prime}}$. It is worth mentioning that 0.02 is conservatively considered as an upper bound for confined concrete ultimate strain. The steel reinforcement of the beams is characterised by yield and ultimate stresses equal to $f_{y}=300 \mathrm{MPa}$ and $f_{u}=390 \mathrm{MPa}$, respectively. A more resistant steel is used for the columns, with $f_{y}=450 \mathrm{MPa}$ and $f_{u}=585 \mathrm{MPa}$, reflecting a common practice in existing buildings (e.g. in building \#39 in Pampanin et al., 2012). In both cases, steel is modelled according to King et al. [1986], considering an elastic modulus $E_{s}=200 \mathrm{GPa}$ and an ultimate strain $\varepsilon_{s u}=0.06$. The mean material properties are 
used in the mechanical characterisation of the members for all the analyses.

The storey seismic weight is constant along the height and it is approximately equal to $1035 \mathrm{kN}$ and $2017 \mathrm{kN}$ for the 2- and 4-bays buildings, respectively. This is done by considering a concrete density equal to $\rho_{\mathrm{c}}=25 \mathrm{kN} / \mathrm{m}^{3}$, a superimposed dead load $\mathrm{D}_{\mathrm{sdl}}=0.5 \mathrm{kN} / \mathrm{m}^{2}$ and a live load $\mathrm{Q}=3 \mathrm{kN} / \mathrm{m}^{2}$ reduced by a factor $\phi_{\mathrm{e}}=0.3$ (NZS1170.5, 2004). The axial load on the columns is calculated based on tributary areas.

\subsection{Case studies}

\subsubsection{Beam-Sway sub-set (BS)}

The frames of this group are designed according to Direct Displacement-Based Design [DDBD, Priestley et al., 2007] and capacity design provisions. Although no specific code/standard is adopted for the design, the reinforcement details of the members (shown below) are compliant with the minimum design values for new structures (e.g. NZS 1170.5, 2004, NTC08, 2008). They exhibit a global plastic mechanism in which, at ULS, all the beams have yielded, along with the base section of the ground storey columns. DDBD approach is used imposing a design drift in the critical section, located at the ground storey for frame structures, equal to $1.5 \%$ for 2 - and 4 -storey cases and $1 \%$ for 6-, 8- and 10-storey cases, as suggested in [Priestley et al., 2007]. The seismic demand is defined by a displacement response spectrum compliant with the New Zealand Code [NZS 1170.5, 2004], related to a medium seismic intensity (peak ground acceleration, PGA $=0.25 \mathrm{~g}$ ) and a shallow subsoil (corresponding to an average shear-wave velocity in the top $30 \mathrm{~m}$ of soil of $\mathrm{V}_{\mathrm{s}, 30}=360 \mathrm{~m} / \mathrm{s}$ ). It is worth noting that the design seismic intensity is not relevant for this study, since the main goal is to compare the non-linear static capacity curves calculated with the SLaMA with the results of numerical pushover analyses.

Figure 9 summarises the detailing of the adopted cross sections, along with the axial load ratios for columns. For both beams and columns, the transverse reinforcement ratio is equal to 
$\rho_{\mathrm{t}}=0.75 \%$ in the plastic hinge zones. Five horizontal stirrups with $12 \mathrm{~mm}$ diameter and $f_{y}=450 \mathrm{MPa}$ are provided in the joint panels, specifically designed to avoid shear failure (as confirmed in Section 4.2).

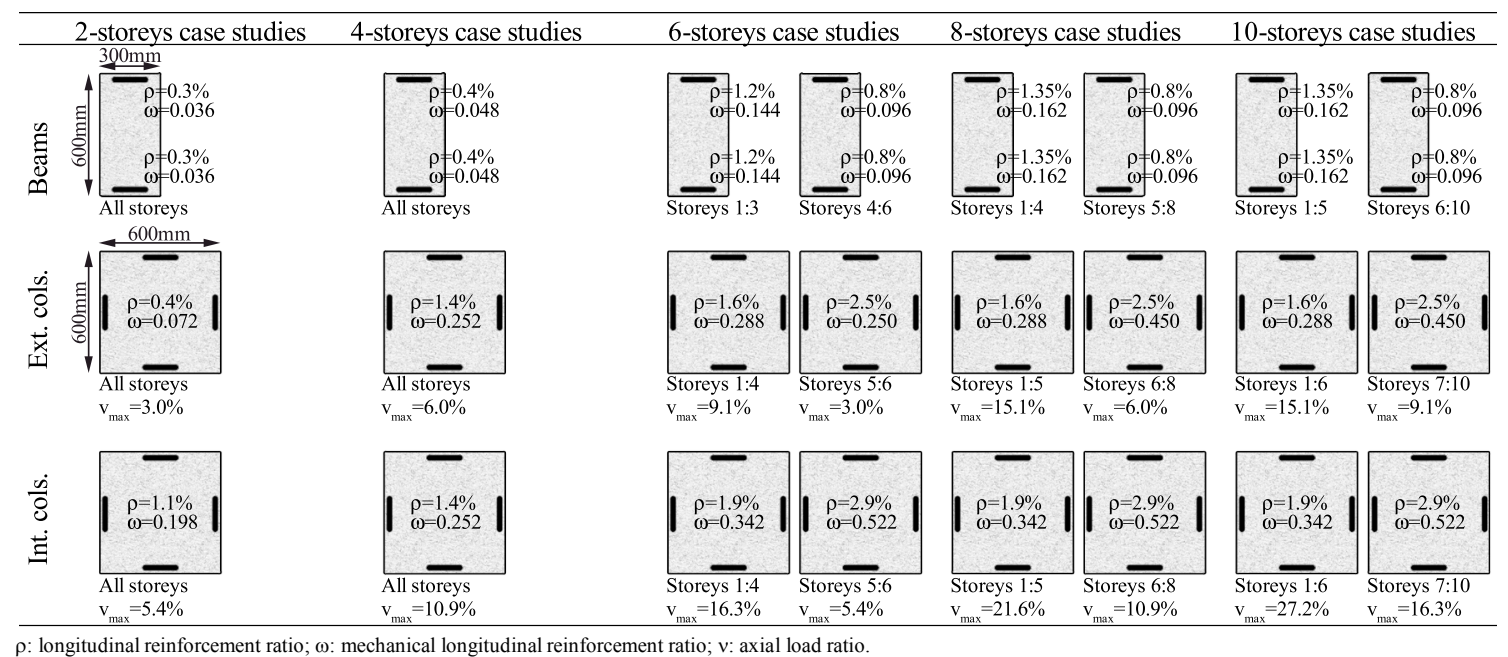

Figure 9 Beam-Sway sub-set: characteristics of beams and columns.

\subsubsection{Mixed-Sway sub-set (MS)}

This group of structures is meant to represent buildings with a level of detailing typical of the 1970s (e.g. NZS1900, 1965), when capacity design principles were not yet introduced and the detailing of the joint shear reinforcement was not adequate to sustain seismic actions. In such conditions, shear cracking or shear failure of columns and joints might develop. The frames of this sub-set are obtained starting from the Beam-Sway sub-set, introducing structural weaknesses for the joints. In particular, no transverse reinforcement is considered in the joints and their principal tensile stress is limited to $0.3 \sqrt{f_{c}}$. The diameter of the transverse reinforcement of beams and columns is reduced and the spacing increased $\left(\rho_{\mathrm{t}}=0.38 \%\right.$ ), in order to represent under-designed members typical of older RC structures (NZSEE 2017). The expected plastic mechanism for this sub-set of frames is characterised by a combination of beam and/or column plastic hinges and joint panels shear failure, called "shear hinge".

\subsubsection{Column-Sway, soft storey at Ground sub-set (CSg)}

This sub-set represents pre-1970s frames designed for gravity loads only. The mechanical characteristics of the beams are equal to the Beam-Sway sub-set. The columns have a square cross- 
section with a $300 \mathrm{~mm}$-side, and a reduced longitudinal reinforcement such that the flexural strength of the columns at the ground storey is equal to $40 \%$ of the strength of the beams, thus allowing the undesirable "strong beam-weak column", typical of gravity-designed frames. Moreover, the transverse reinforcement ratio of the columns is reduced to $\rho_{\mathrm{t}}=0.2 \%$, as observed in real pre- $1970 \mathrm{~s}$ buildings (Pampanin et al., 2012). In this sub-set, rigid behaviour is reasonably assumed for the joint panels, since the expected failure mechanism is a soft storey located at the ground storey.

\subsubsection{Column-Sway, soft storey at Mid-Height sub-set (CSmh)}

This sub-set is meant to represent another typical situation for pre-1970s gravity-dominated frames: the reduction of the cross-section of the columns along the height due to the reduced gravity load. The mechanical characteristics of the beams are equal to the Beam-Sway sub-set. The columns have a $400 \times 400 \mathrm{~mm}$ square cross-section, reducing to $300 \times 300 \mathrm{~mm}$ at the building mid-height, where they have a flexural strength equal to $40 \%$ of the strength of the concurrent beams. Their transverse reinforcement ratio is $\rho_{\mathrm{t}}=0.2 \%$. For these reasons, a soft-storey mechanism is expected to develop at mid height of the building. As per the CSgf group, rigid behaviour is assumed for the joint panels.

\subsection{Numerical modelling assumptions}

A numerical pushover analysis is performed for each frame using the software Ruaumoko [Carr, 2016]. The analyses are conducted in displacement-control and applying a linear force profile, consistently with the assumptions used in SLaMA. Since the aim of this work is the SLaMA vs numerical pushover validation only, the soft-storey case studies are not re-assessed using a uniform force profile. P-Delta effects are neglected. This assumption is justified in Section 4. The analyses are terminated when the first member in the system reaches its ultimate displacement capacity. The floor slabs are modelled as rigid diaphragms. Fully fixed boundary conditions are considered at the base of the columns.

The adopted modelling strategy (schematised in Figure 10) was extensively validated against experimental tests both at sub-assembly and frame level [Magenes and Pampanin, 2004, Gentile et 
al. 2017a]. A lumped plasticity approach is adopted for beams and columns, which are modelled by means of mono-dimensional Giberson elements [Sharpe, 1976]. The beams are characterised by means of tri-linear Moment-Curvature relationships and plastic hinge length (see section 2.1 for details) while for columns a Moment-Axial load domain is used to account for the variation of their capacity caused by the variation of axial load due to the frame Sway. Plastic hinge length ranges between $5.9 \%$ and $7.4 \%$ of the length for beams, and between $7.7 \%$ and $16.2 \%$ for columns. According to the state-of-the-art practice, hardening is considered for both beams and columns. Moment-Curvature analysis is performed using the software Cumbia [Montejo and Priestley, 2007] and the potential flange effect is accounted for with a $30 \%$ increase in the negative moment capacity. The ultimate drift of such members is calibrated considering the alternative failure mechanisms as per Section 2.1 and Table 1. Rigid ends are used for beam and column members, which in turn are connected with non-linear lumped springs (two for each geometrical node of the frame) used to model the joint panel. The non-linear behaviour of these springs is set consistently with the Equivalent Column Moment-joint drift relationships, depicted in Figure 2.
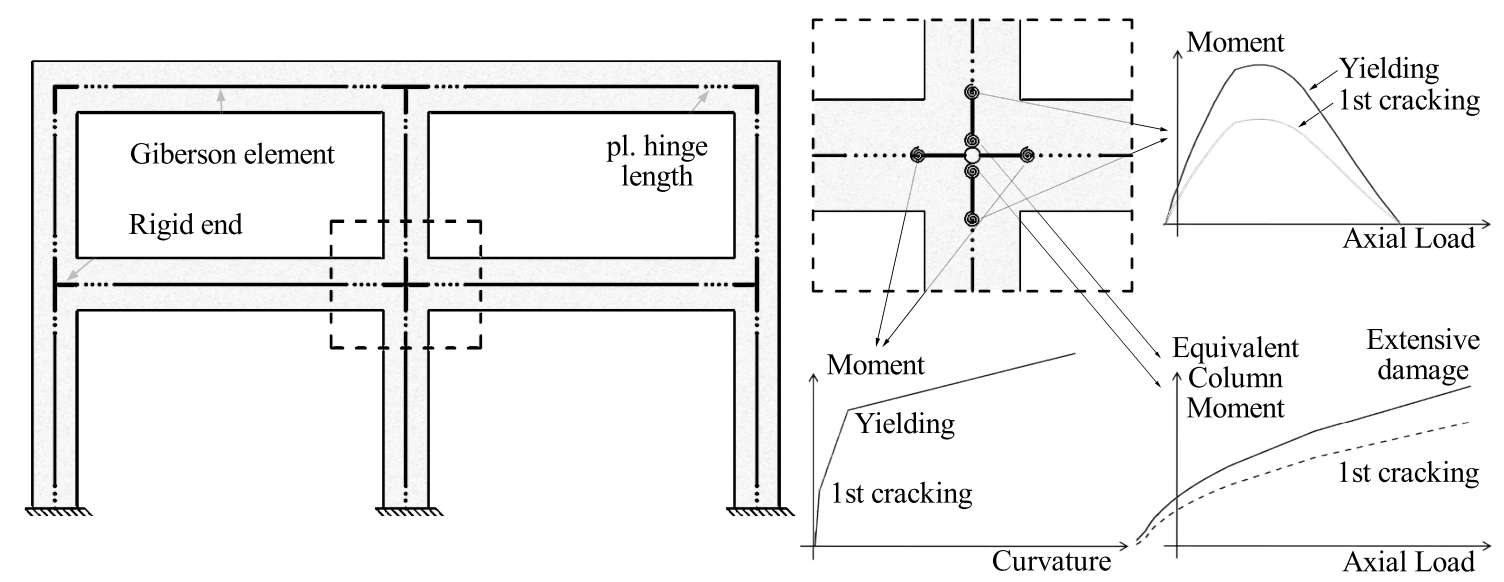

Figure 10 Numerical modelling strategy.

\section{Results}

The accuracy of the SLaMA is assessed by comparing the results with the refined numerical pushover capacity curves and estimating the percentage error $\left(\operatorname{Err}(\%)=\frac{S L a M A-P . O}{P . O .}\right)$ for a number of selected 
parameters. First, the accuracy of the NZSEE 2017 version of the SLaMA procedure is assessed. Then, the improvements related to the use of the refined SLaMA are quantified. The synthetic description of the results allows to highlight the influence of the proposed refinements. Therefore, detailed results for the refined SLaMA are shown for selected cases, one for each sub-set, including the capacity curve, plastic mechanism and displacement profile.

The numerical curves are bi-linearised by considering the stiffness secant to the $1^{\text {st }}$ formed hinge in the system and calculating equivalent yield displacement applying the equal energy rule (as suggested in ATC40, 1996 to estimate the effective period of the equivalent SDOF system and compare the capacity with the demand in the form of a response spectrum). Although a different bilinear fitting might give better estimation of the equivalent yield displacement (FEMA, 2009), this fitting method is adopted since it allows to define the hardening branch. The parameters selected for the comparison are the base shear, the effective height and the displacement at the effective height, calculated at yielding and Ultimate Limit State (ULS), and the secant-to-yielding stiffness. The effective height for the pushover analyses has been calculated with Eq. 5, based on the numericallycalculated displacement profile. Moreover, the hierarchy of strength, the displacement profile and the full capacity curve are compared in a graphical fashion, for selected cases (one for each sub-set). Graphical results are available in Gentile, 2017 for the complete set of case study frames.

It is worth stating that the main purpose of SLaMA is the assessment of existing structures. Hence, in most cases, the calculated capacity curve is used to perform a capacity/demand check in the Acceleration-Displacement Response Spectrum (e.g. capacity spectrum method, ATC, 1996, or the percentage of building standard, NZSEE 2017). To this scope, the ultimate base shear and displacement are deemed to be the most relevant parameters.

\subsection{Accuracy of SLAMA and influence of the proposed refinements}

In this section, the SLaMA-to-numerical percentage errors related to the NZSEE 2017 and the refined SLaMA procedures are compared. It is worth mentioning that since the NZSEE 2017 SLaMA procedure is not applicable for soft-storey mechanisms located at mid height of the building, the 
comparison is only possible for the Beam-Sway, Mixed-Sway and Column-Sway ground storey subsets. Figure 11 reports the comparison for each selected parameter: ultimate displacement (Figure 14a,b), ultimate base shear (Figure 14c,d), effective height (Figure 14a e,f), yield displacement (Figure 14a g,h) and initial stiffness (Figure 14a i,j). The capacity curves for the entire database, defined by means of the base shear and displacement at the significant points, are summarised in Table 3, both for the refined SLaMA and the numerical analyses. Figure 12 shows the pushover curves resulting from the numerical analyses. An in-depth discussion on the refined SLaMA results for each sub-set in the database is given in sections 3.2.1 to 3.2.4. It is worth mentioning that the numerical analyses have been repeated, by considering P-Delta effects, for the 4 tallest and widest case studies in the database. At the ultimate point, a maximum reduction in base shear with respect to the first-order analyses has been observed to be smaller than $10 \%$, thus supporting the assumption of neglecting P-Delta effects.

For the Beam-Sway and Mixed-Sway sub-sets, the NZSEE2017 and the refined SLaMA procedures provide similar results and reasonable biases in terms of ultimate displacement $(-20 \%$, $20 \%$ ). However, by using the proposed refinements, a substantial improvement in the estimation of the ultimate displacement is observed for frames exhibiting a Column-Sway mechanism at the ground storey. Indeed, for such cases the SLaMA 2017 procedure overestimates the ultimate displacement up to $200 \%$, while for the refined SLaMA the mean error is below $20 \%$. However, as discussed in section 4.4, it is not recommended to use the refined SLaMA to calculate the Column-Sway capacity curve of frames with more than 6 storeys.

In the refined procedure, the base shear at ULS is predicted with less than $10 \%$ error for the majority of the cases, compared to $20 \%$ average for the SLaMA 2017. It is deemed that such an improvement is due to the increased accuracy in the prediction of the effective height. Very simple formulations for the effective height are suggested in SLaMA 2017, leading to under predictions for this parameter up to $35 \%$. On the other hand, the refined procedure allows to contain the error between $0.1 \%$ and $7.4 \%$. 
The refined SLaMA leads to a high dispersion $(-30 \%,+75 \%)$ in the estimation of the yield displacement, and this is higher than the NZSEE 2017 procedure. Based on the observed error trends, further research is needed to improve the prediction of this parameter, especially at sub-assembly level. However, the observed error on the yield base shear (due to the elastic-perfectly plastic assumption in SLaMA) counterbalances the error on the yield displacement in the estimation of the initial stiffness. Regarding such a parameter, the refinements to the SLaMA procedure allow to narrow the error bandwidth, which ranges from $(-60 \%,+60 \%)$ for SLaMA 2017 to $(-40 \%,+20 \%)$ for the refined SLaMA.

Although the accuracy and reliability of the NZSEE 2017 version of the SLaMA is satisfactory, the proposed refinements are deemed to improve the construction of the capacity curve. As an improvement of the original procedure, the refinements allow to analyse frames with an expected soft-storey mechanism at any level and also allow the calculation of the displacement profile for both global and local plastic mechanisms. A detailed analysis for the different sub-sets of the case study frames is reported in the following. 

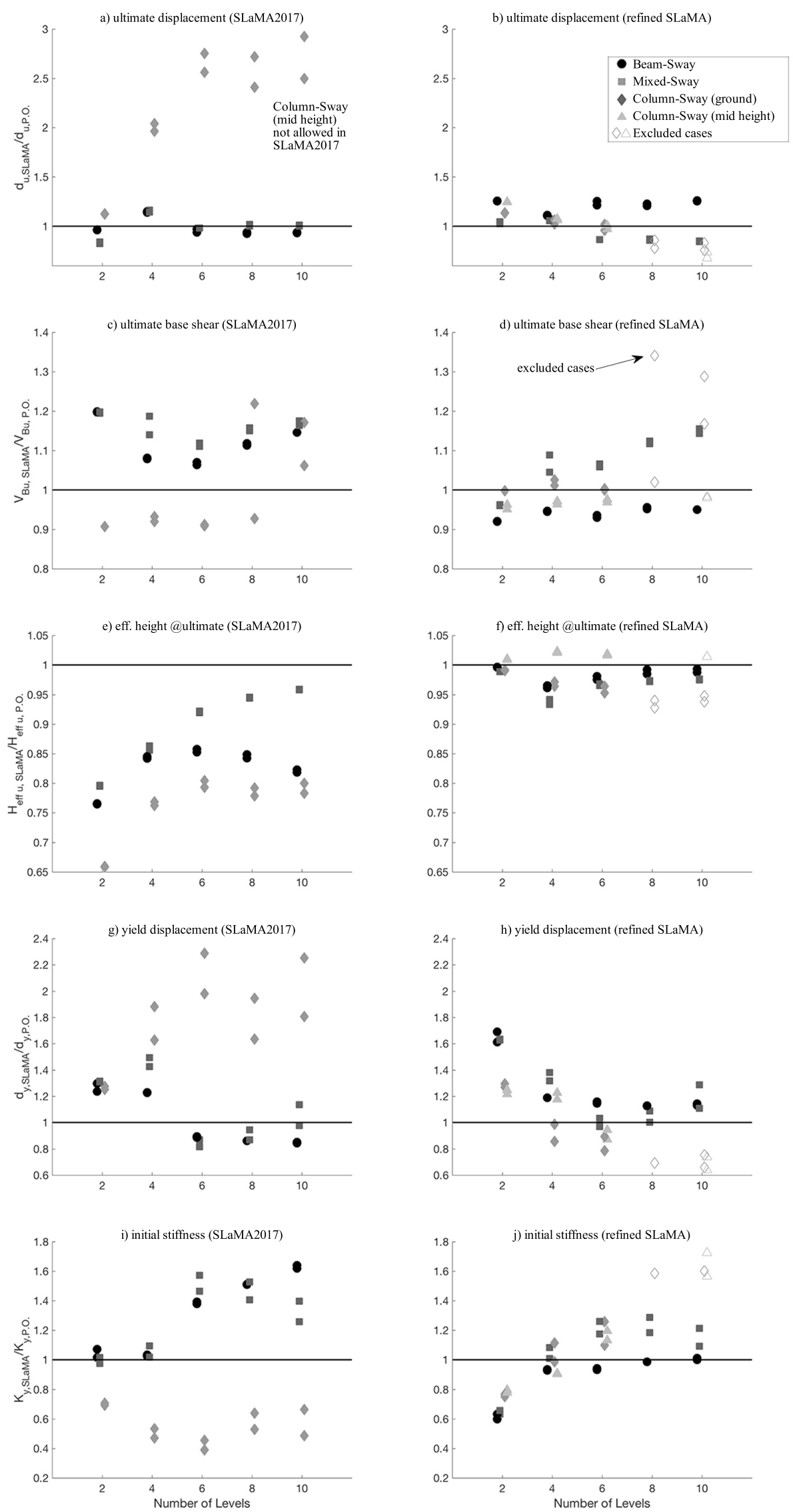

Figure 11 SLaMA-to-numerical error for both the NZSEE 2017 and refined SLaMA. 
Table 3 Significant points of the numerical pushover curve for the entire database. The results for the refined SLAMA are reported in brackets.

\begin{tabular}{|c|c|c|c|c|c|c|c|c|c|}
\hline \multicolumn{2}{|c|}{ Case Study } & \multicolumn{2}{|c|}{$\Delta \mathrm{y}[\mathrm{cm}]$} & \multicolumn{2}{|c|}{$\Delta \mathrm{u}[\mathrm{cm}]$} & \multicolumn{2}{|c|}{$\mathrm{V}_{\mathrm{By}}[\mathrm{kN}]$} & \multicolumn{2}{|c|}{$\mathrm{V}_{\mathrm{Bu}}[\mathrm{kN}]$} \\
\hline \multirow[t]{10}{*}{ BS } & $2 \mathrm{~b} 2 \mathrm{~s}$ & 1.17 & $(1.97)$ & 13.41 & $(16.79)$ & 382.3 & $(387.0)$ & 420.8 & $(387.0)$ \\
\hline & $2 \mathrm{~b} 4 \mathrm{~s}$ & 2.55 & (3.04) & 23.85 & (26.53) & 485.2 & (539.7) & 570.1 & (539.7) \\
\hline & $2 \mathrm{~b} 6 \mathrm{~s}$ & 5.71 & (6.60) & 43.89 & (55.07) & 848.3 & (915.2) & 978.2 & (915.2) \\
\hline & $2 \mathrm{~b} 8 \mathrm{~s}$ & 7.60 & $(8.55)$ & 59.01 & (71.26) & 836.6 & (929.0) & 971.7 & (929.0) \\
\hline & $2 \mathrm{~b} 10 \mathrm{~s}$ & 9.28 & (10.49) & 69.89 & $(87.50)$ & 795.3 & (909.9) & 958.2 & (909.9) \\
\hline & $4 \mathrm{~b} 2 \mathrm{~s}$ & 1.23 & (1.97) & 13.37 & (16.79) & 772.7 & (787.5) & 855.6 & (787.5) \\
\hline & $4 \mathrm{~b} 4 \mathrm{~s}$ & 2.55 & (3.04) & 24.03 & (26.53) & 915.9 & (1009.2) & 1068.0 & (1009.2) \\
\hline & $4 \mathrm{~b} 6 \mathrm{~s}$ & 5.77 & (6.60) & 45.44 & (55.07) & 1649.1 & (1779.0) & 1913.0 & (1779.0) \\
\hline & $4 \mathrm{~b} 8 \mathrm{~s}$ & 7.58 & $(8.55)$ & 58.11 & (71.26) & 1629.7 & (1814.4) & 1906.0 & (1814.4) \\
\hline & $4 \mathrm{~b} 10 \mathrm{~s}$ & 9.19 & (10.49) & 69.51 & $(87.50)$ & 1560.2 & (1781.7) & 1876.0 & (1781.7) \\
\hline \multirow[t]{10}{*}{ MS } & $2 \mathrm{~b} 2 \mathrm{~s}$ & 1.21 & (1.98) & 5.37 & $(5.50)$ & 355.7 & $(366.7)$ & 381.9 & $(366.7)$ \\
\hline & $2 \mathrm{~b} 4 \mathrm{~s}$ & 2.29 & (3.02) & 7.61 & (8.18) & 336.0 & (479.9) & 440.9 & (479.9) \\
\hline & $2 \mathrm{~b} 6 \mathrm{~s}$ & 6.43 & (6.64) & 13.51 & (11.65) & 731.9 & (887.0) & 838.4 & (887.0) \\
\hline & $2 \mathrm{~b} 8 \mathrm{~s}$ & 7.89 & (8.59) & 17.40 & (15.13) & 692.6 & (893.7) & 795.1 & (893.7) \\
\hline & $2 \mathrm{~b} 10 \mathrm{~s}$ & 8.20 & (10.54) & 21.87 & (18.62) & 628.0 & (881.2) & 763.1 & (881.2) \\
\hline & $4 \mathrm{~b} 2 \mathrm{~s}$ & 1.21 & (1.98) & 5.27 & $(5.50)$ & 717.1 & (766.8) & 796.3 & (766.8) \\
\hline & $4 \mathrm{~b} 4 \mathrm{~s}$ & 2.18 & (3.02) & 7.74 & (8.18) & 680.5 & (948.4) & 907.7 & (948.4) \\
\hline & $4 \mathrm{~b} 6 \mathrm{~s}$ & 6.85 & (6.64) & 13.51 & (11.65) & 1433.3 & (1749.8) & 1642.0 & (1749.8) \\
\hline & $4 b 8 s$ & 8.57 & $(8.59)$ & 17.65 & (15.13) & 1379.3 & (1778.5) & 1592.0 & (1778.5) \\
\hline & $4 \mathrm{~b} 10 \mathrm{~s}$ & 9.53 & (10.54) & 22.09 & (18.62) & 1305.8 & (1753.3) & 1534.0 & (1753.3) \\
\hline \multirow[t]{10}{*}{$\mathrm{CSg}$} & $2 \mathrm{~b} 2 \mathrm{~s}$ & 1.89 & $(2.44)$ & 3.55 & $(4.02)$ & 76.8 & $(74.5)$ & 74.6 & $(74.5)$ \\
\hline & $2 \mathrm{~b} 4 \mathrm{~s}$ & 2.30 & (1.97) & 2.39 & (2.44) & 101.0 & (96.5) & 94.1 & (96.5) \\
\hline & $2 \mathrm{~b} 6 \mathrm{~s}$ & 2.42 & (1.90) & 2.84 & (2.72) & 208.0 & (205.4) & 204.8 & (205.4) \\
\hline & $2 b 8 s$ & 3.29 & (1.97) & 3.50 & $(2.72)$ & 320.4 & (304.5) & 298.5 & (304.5) \\
\hline & $2 \mathrm{~b} 10 \mathrm{~s}$ & 2.67 & (1.76) & 3.01 & $(2.28)$ & 215.4 & (283.5) & 220.1 & $(283.5)$ \\
\hline & $4 \mathrm{~b} 2 \mathrm{~s}$ & 1.92 & $(2.44)$ & 3.54 & $(4.02)$ & 138.9 & (134.9) & 135.2 & (134.9) \\
\hline & $4 b 4 s$ & 1.99 & (1.96) & 2.29 & (2.43) & 160.1 & (155.9) & 154.1 & (155.9) \\
\hline & $4 \mathrm{~b} 6 \mathrm{~s}$ & 2.09 & (1.87) & 2.64 & (2.69) & 335.0 & (328.4) & 328.6 & (328.4) \\
\hline & $4 \mathrm{~b} 8 \mathrm{~s}$ & 2.76 & (1.91) & 3.11 & (2.67) & 360.0 & (491.5) & 366.6 & (491.5) \\
\hline & $4 \mathrm{~b} 10 \mathrm{~s}$ & 2.14 & (1.61) & 2.57 & (2.13) & 341.6 & (411.1) & 352.1 & (411.1) \\
\hline \multirow[t]{10}{*}{$\mathrm{CSmh}$} & $2 \mathrm{~b} 2 \mathrm{~s}$ & 1.83 & $(2.22)$ & 6.53 & $(8.13)$ & 126.5 & (122.4) & 128.7 & (122.4) \\
\hline & $2 \mathrm{~b} 4 \mathrm{~s}$ & 2.03 & (2.39) & 3.83 & $(4.06)$ & 119.4 & (127.6) & 132.5 & (127.6) \\
\hline & $2 \mathrm{~b} 6 \mathrm{~s}$ & 2.79 & (2.43) & 5.11 & $(4.97)$ & 273.1 & $(284.5)$ & 293.9 & (284.5) \\
\hline & $2 \mathrm{~b} 8 \mathrm{~s}$ & 2.97 & $(2.12)$ & 4.38 & (3.35) & 279.4 & (299.5) & 307.8 & (299.5) \\
\hline & $2 \mathrm{~b} 10 \mathrm{~s}$ & 3.89 & (2.49) & 5.14 & (3.47) & 301.7 & $(333.0)$ & 340.1 & $(333.0)$ \\
\hline & $4 \mathrm{~b} 2 \mathrm{~s}$ & 1.77 & $(2.21)$ & 6.54 & (8.13) & 222.7 & (216.2) & 224.7 & $(216.2)$ \\
\hline & $4 b 4 s$ & 1.95 & (2.39) & 3.78 & (4.07) & 207.5 & (229.7) & 236.6 & (229.7) \\
\hline & $4 \mathrm{~b} 6 \mathrm{~s}$ & 2.58 & $(2.43)$ & 4.93 & (4.97) & 470.1 & (502.2) & 514.8 & $(502.2)$ \\
\hline & $4 \mathrm{~b} 8 \mathrm{~s}$ & 2.72 & (2.14) & 4.19 & (3.37) & 495.0 & (545.3) & 557.4 & (545.3) \\
\hline & $4 \mathrm{~b} 10 \mathrm{~s}$ & 3.40 & $(2.50)$ & 4.72 & (3.48) & 517.4 & (596.3) & 606.9 & (596.3) \\
\hline
\end{tabular}

BS - Beam-Sway; MS - Mixed-Sway; CSg - Column-Sway (ground); CSmh - Column-Sway (mid height);

$\mathrm{b}$ - bays; $\mathrm{s}-$ storeys. 

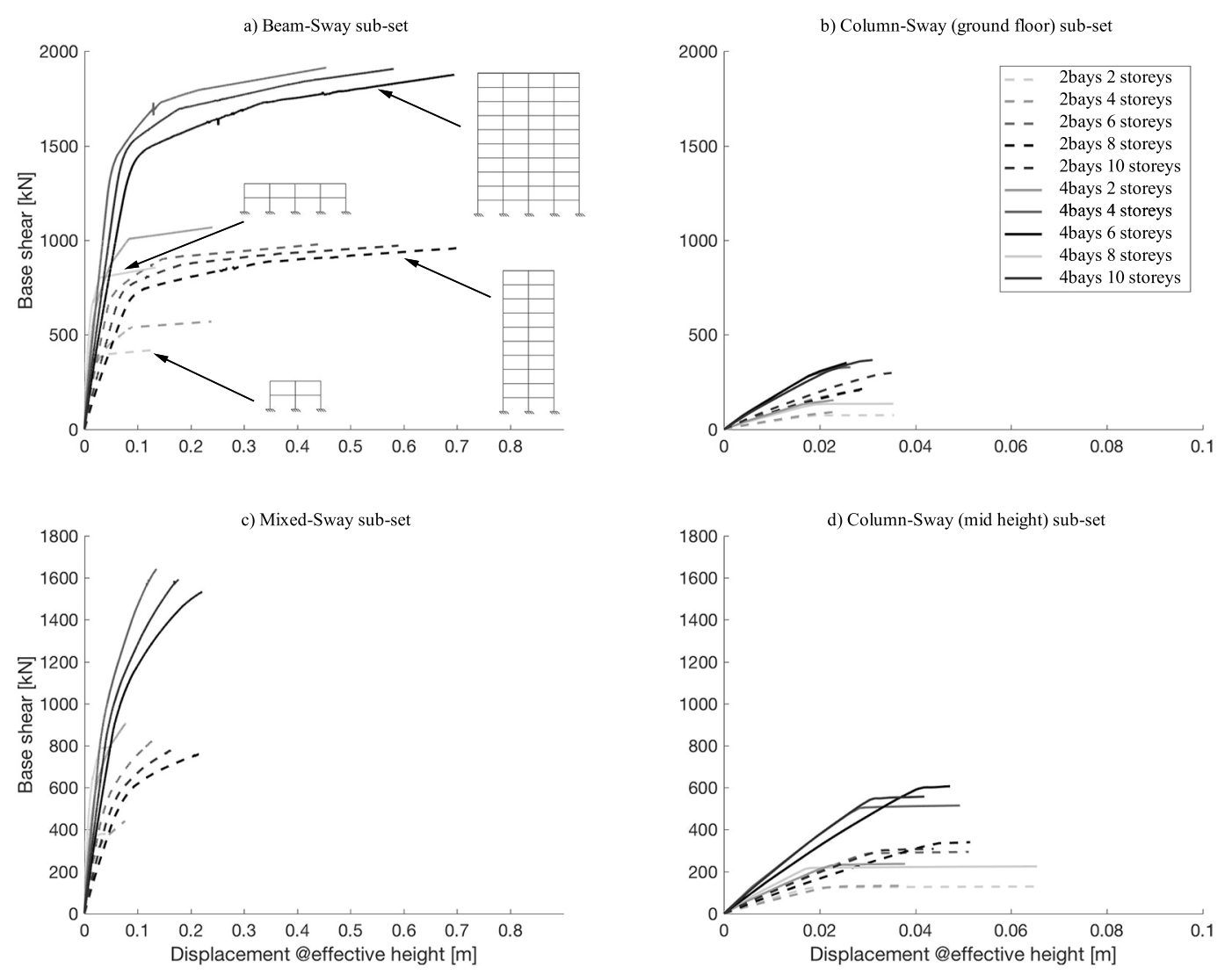

Figure 12 Numerical pushover capacity curves for the entire database.

\subsection{Beam-Sway sub-set (BS)}

For the studied Beam-Sway type frames, the ductility capacity of the beam that yields first (highlighted by a red circle in Figure 13.a and Figure 13.b) allows for a full redistribution of the internal actions, leading to a fully developed global mechanism. The hierarchy of strength is perfectly captured by SLaMA for all cases (compared in Figure 13 with the pushover-based plastic mechanism). It is worth repeating that the proposed refinements to the SLaMA procedure are considered in this discussion. The same result is found for the effective height (maximum $1 \%$ error, see Table 4). This leads to underestimate the ultimate base shear $(8 \%$, on average), which is due to the hardening in the members, neglected in SLaMA. Figure 13.d reports the results of the numerical pushover analysis carried out neglecting the hardening in the beam flexural strength. In this case, the error of the SLaMA procedure related to the ultimate base shear is zero, demonstrating the high accuracy of the procedure. The significant overestimation registered for the base shear at yielding 
(13\% maximum) is due to assuming that all beams exploit the yielding moment demand at the yielding of the frame (which, in SLaMA, corresponds to the yielding of the first beam). This trend is consistent for all the case studies. Neglecting the strength hardening of the members approximately produces a $10 \%$ under-estimation of the base shear, as outlined in Figure 13d. Indeed, neglecting hardening in SLaMA results in a slight and conservative under-estimation of the peak strength.

The prediction of the displacement profile by using the refined SLaMA, both at yielding and ultimate, overestimates the numerical results (Figure 13.c). In particular, a 22\% average error is registered for the yielding displacement at the effective height. On the other hand, the error on the ultimate displacement is approximately equal to $18 \%$.

Table 4 BS sub-set SLaMA vs numerical [\%].

\begin{tabular}{|c|c|c|c|c|c|c|c|c|}
\hline CASE & & $\operatorname{Err}\left(\mathrm{H}_{\mathrm{eff}, \mathrm{y}}\right)$ & $\operatorname{Err}\left(\mathrm{H}_{\text {eff,y }}\right)$ & $\operatorname{Err}\left(\delta_{\mathrm{y}}\right)$ & $\operatorname{Err}\left(\delta_{\mathrm{u}}\right)$ & $\operatorname{Err}\left(\mathrm{V}_{\mathrm{By}}\right)$ & $\operatorname{Err}\left(V_{\mathrm{Bu}}\right)$ & $\operatorname{Err}\left(K_{y}\right)$ \\
\hline \multirow[t]{5}{*}{ 2-bays } & 2-storeys & -0.4 & -0.3 & 68.9 & 25.2 & 1.2 & -8.0 & -40.8 \\
\hline & 4-storeys & -2.6 & -3.9 & 18.9 & 11.2 & 11.2 & -5.3 & -15.9 \\
\hline & 6-storeys & -0.1 & -0.4 & 7.0 & 16.0 & 5.7 & -8.4 & -13.6 \\
\hline & 8-storeys & -0.5 & -0.1 & 7.0 & 14.8 & 9.4 & -5.8 & -11.1 \\
\hline & 10 -storeys & -1.2 & -0.5 & 10.2 & 22.0 & 13.5 & -5.8 & -11.6 \\
\hline \multirow[t]{5}{*}{ 4-bays } & 2-storeys & -0.2 & -0.4 & 61.1 & 25.6 & 1.9 & -8.0 & -37.9 \\
\hline & 4-storeys & -2.1 & -3.5 & 18.8 & 10.4 & 10.2 & -5.5 & -15.8 \\
\hline & 6-storeys & 0.3 & 0.1 & 5.9 & 12.0 & 5.7 & -8.9 & -12.7 \\
\hline & 8 -storeys & 0.0 & 0.7 & 7.2 & 16.6 & 9.7 & -6.2 & -11.3 \\
\hline & 10 -storeys & -0.7 & 0.1 & 11.4 & 22.7 & 13.3 & -5.7 & -12.5 \\
\hline \multicolumn{2}{|c|}{ Mean error } & -0.8 & -0.8 & 21.6 & 17.7 & 8.2 & -6.8 & -18.3 \\
\hline
\end{tabular}



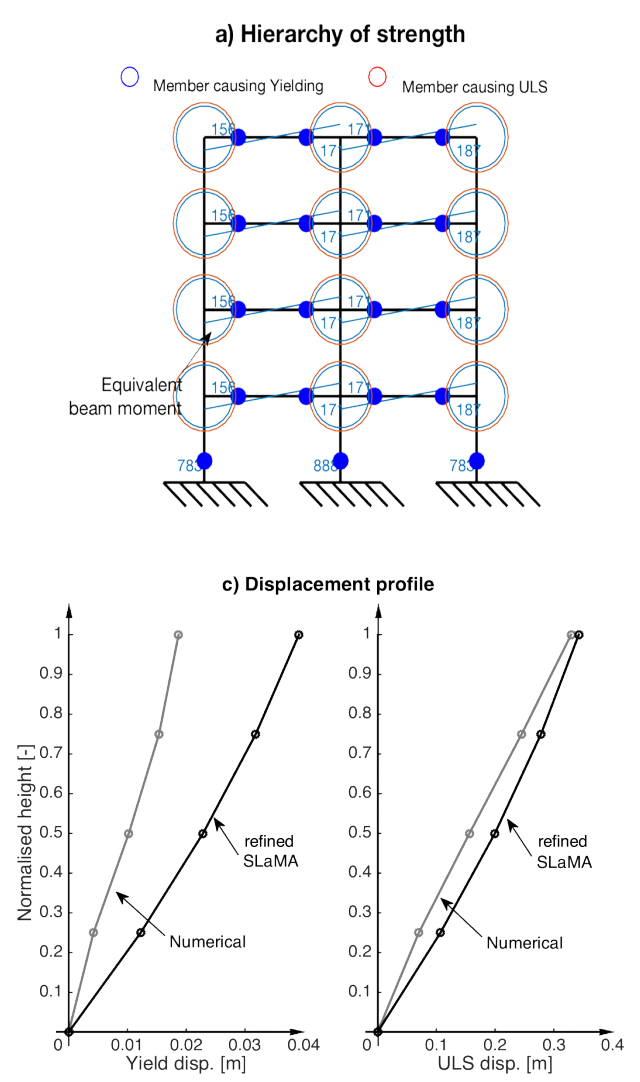
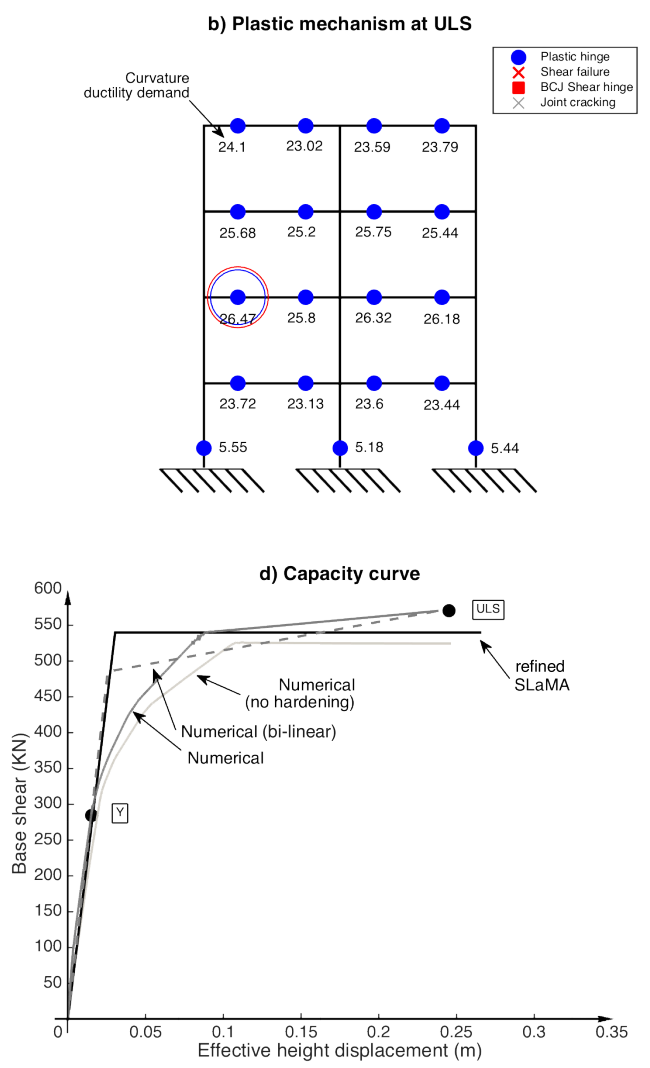

Figure 13 BS 2-bays, 4-storeys: summary of the results.

\subsection{Mixed-Sway sub-set (MS)}

In the case study frames of this sub-set, the ultimate displacement capacity of the structure is governed by the beam-column joint that first reaches its ultimate deformation capacity (highlighted in a red circle in Figure 14). This strongly affects the possibility to redistribute the internal actions and hence the formation of a global plastic mechanism. Among the analysed case studies, full redistribution is only achieved for frames up to 4 storeys. For example, Figure 13 shows the results of the refined SLaMA for the 6-storeys frame, which does not develop a full mechanism. The assumption, in SLaMA, of calculating the ultimate base shear assuming the development of the full strength of all the sub-assemblies results in an overestimation. This error monotonically increases with the number of storeys (maximum 15\%, see Table 5 and Figure 14.d). For the same reason discussed in section 4.1, a higher overestimation of the base shear at yielding is registered ( $25 \%$ on average). 
The ultimate displacement profile and, in turn, the ultimate displacement at the effective height, is reasonably well-predicted for frames exhibiting a Mixed-Sway mechanism. In particular, for the cases in which the frame ULS is governed by the failure of a joint panel, the ultimate displacement is slightly overestimated (about 3\%). A good match can be observed for the yield displacement of the 6-, 8-, 10-storeys frames, while a great over-estimation rises for the 2- and 4storeys cases.

Finally, similarly to the results observed for the Beam-Sway sub-set (section 4.1), the effective height shows an almost perfect match between SLaMA and numerical pushover. This confirms that the assumed displacement shapes in the refined SLaMA procedure are appropriate.

Table 5 MS sub-set SLaMA vs numerical error [\%].

\begin{tabular}{llrrrrrrr}
\hline CASE & & $\operatorname{Err}\left(\mathrm{H}_{\mathrm{eff}, \mathrm{y}}\right)$ & $\operatorname{Err}\left(\mathrm{H}_{\mathrm{eff}, \mathrm{y}}\right)$ & $\operatorname{Err}\left(\delta_{\mathrm{y}}\right)$ & $\operatorname{Err}\left(\delta_{\mathrm{u}}\right)$ & $\operatorname{Err}\left(\mathrm{V}_{\mathrm{By}}\right)$ & $\operatorname{Err}\left(\mathrm{V}_{\mathrm{Bu}}\right)$ & $\operatorname{Err}\left(\mathrm{K}_{\mathrm{y}}\right)$ \\
\hline 2-bays & 2-storeys & -0.7 & -1.0 & 63.4 & 2.5 & 3.1 & -4.0 & -38.8 \\
& 4-storeys & -3.5 & -6.7 & 31.8 & 7.5 & 42.8 & 8.8 & -24.1 \\
& 6-storeys & -0.2 & -1.5 & -4.6 & 1.0 & 18.7 & 3.6 & -3.1 \\
& 8-storeys & -0.4 & -1.4 & 3.5 & -2.7 & 27.2 & 10.8 & -8.2 \\
& 10-storeys & -1.2 & -1.8 & 25.3 & -9.7 & 39.3 & 14.6 & -22.2 \\
4-bays & 2-storeys & -0.4 & -1.1 & 62.8 & 4.4 & 6.9 & -3.7 & -38.6 \\
& 4-storeys & -2.6 & -5.8 & 38.1 & 5.7 & 39.4 & 4.5 & -27.6 \\
& 6-storeys & 0.1 & -1.2 & -10.5 & 1.0 & 19.6 & 4.4 & 3.3 \\
& 8-storeys & 0.0 & -1.2 & -4.7 & -4.1 & 27.1 & 10.1 & -0.2 \\
& 10-storeys & -0.6 & -1.6 & 7.9 & -10.6 & 33.2 & 13.4 & -9.7 \\
\multicolumn{1}{l}{ Mean error } & -1.0 & -2.3 & 21.3 & -0.5 & 25.7 & 6.3 & -16.9 \\
\hline
\end{tabular}



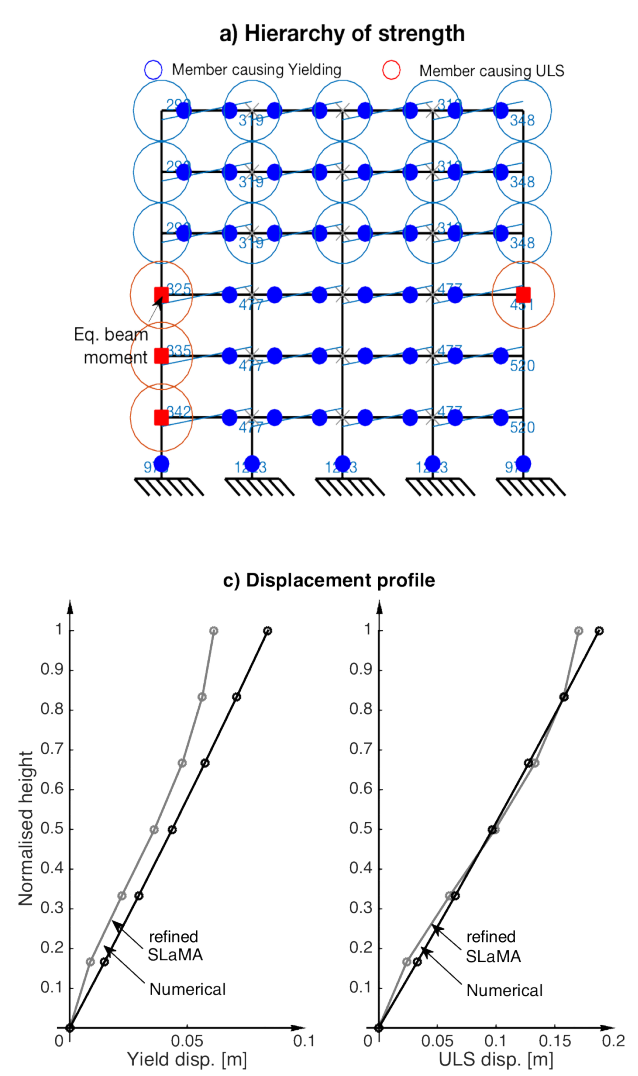
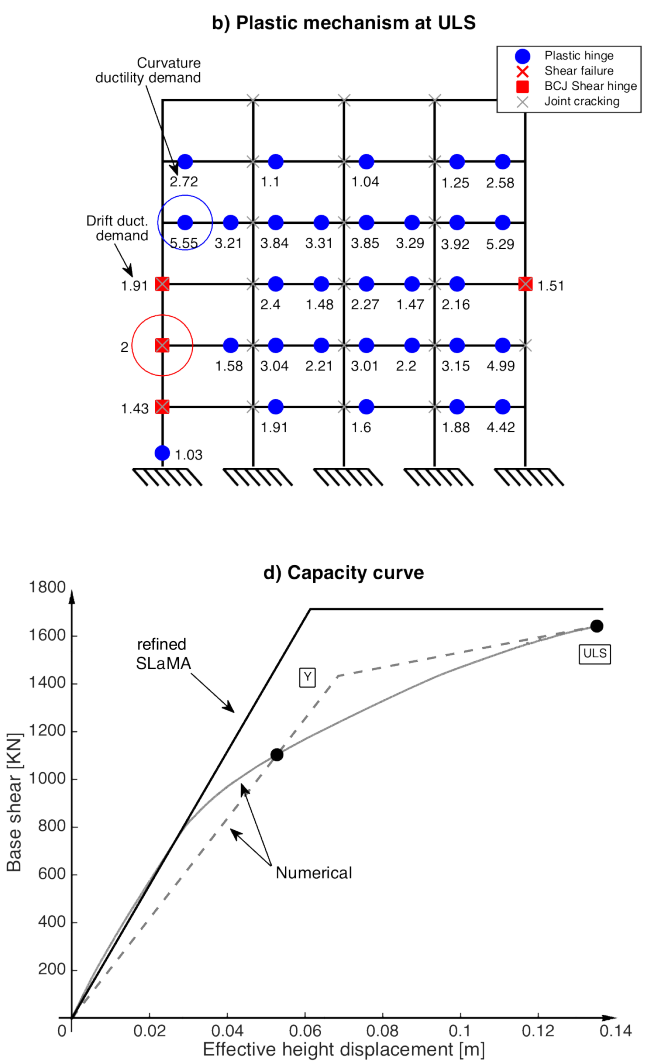

Figure 14 MS 4-bays, 6-storeys: summary of the results.

\subsection{Column-Sway sub-sets: ground (CSg) and mid-height (CSmh)}

Similar results can be observed applying the refined SLaMA to the two sub-sets of frames experiencing a soft-storey mechanism. Hence, the related results are presented together. For all the case study frames, the hierarchy of strength calculations allow to accurately predict the location of the soft storey (see, for example, Figure 15a,b and Figure 16a,b). Thus, it can be generalised that the proposed procedure for Column-Sway mechanisms can be used to detect the location of a soft-storey mechanism which may develop at any storey.

The proposed SLaMA procedure is able to predict the base shear capacity of the frame very accurately (Table 6 and Table 7 indicate less than 5\% average over estimation on the yield and ultimate base shear). However, SLaMA greatly overestimates the base shear capacity for tall frames, for which full development of the soft storey is prevented by the drift capacity of the first formed hinge. This happened for the 10 -storey cases with a ground soft-storey (see Table 6 ). 
The effective height, which is not expressly used in the SLaMA calculations for a ColumnSway mechanism, is calculated with great accuracy both at yielding and ultimate (4\% error, in average). This reflects the match between the assumed (SLaMA) and the "actual" (numerical pushover) displacement profiles (see Figure 15.c and Figure 16.c) also for the Column-Sway frames.

The SLaMA procedure is able to accurately predict both the yield and ultimate displacements for frames with 2, 4 and 6 storeys. Conversely, for the 8-and 10-storeys frames there is a great under estimation of these parameters (higher than $20 \%$, see Table 6 and Table 7 ) and this greatly affects the SLaMA capacity curve. This gap is caused by an error in assessing the contribution to the total displacement of the storeys not involved in the soft storey. Since this major error is registered for both the CSg and CSmh sub-sets, it is not recommended to use SLaMA to calculate the ColumnSway capacity curve of frames having more than 6 storeys. For this reason, the average values of the error in Table 6 and Table 7 are referred to the frames with 2, 4 and 6 storeys. Finally, Figure 15.d and Figure 16.d should be compared to assess the different accuracy of SLaMA for short and tall Column-Sway type frames.

Table 6 CSgf-Sway sub-set SLaMA vs numerical error [\%].

\begin{tabular}{|c|c|c|c|c|c|c|c|c|}
\hline CASE & & $\operatorname{Err}\left(\mathrm{H}_{\text {eff,y }}\right)$ & $\operatorname{Err}\left(\mathrm{H}_{\text {eff,y }}\right)$ & $\operatorname{Err}\left(\delta_{\mathrm{y}}\right)$ & $\operatorname{Err}\left(\delta_{\mathrm{u}}\right)$ & $\operatorname{Err}\left(V_{\text {By }}\right)$ & $\operatorname{Err}\left(\mathrm{V}_{\mathrm{Bu}}\right)$ & $\operatorname{Err}\left(\mathrm{K}_{\mathrm{y}}\right)$ \\
\hline \multirow{5}{*}{ 2-bays } & 2-storeys & -1.7 & -0.9 & 29.7 & 13.5 & -3.0 & -0.2 & -22.7 \\
\hline & 4-storeys & -3.7 & -3.6 & -14.3 & 2.3 & -4.5 & 2.6 & 16.7 \\
\hline & 6-storeys & -4.6 & -4.7 & -21.6 & -4.2 & -1.2 & 0.3 & 27.4 \\
\hline & 8-storeys & -6.5 & -7.4 & -40.4 & -22.6 & -5.0 & 2.0 & 66.8 \\
\hline & 10 -storeys & -4.9 & -6.3 & -34.7 & -24.8 & 31.6 & 28.8 & 51.7 \\
\hline \multirow[t]{5}{*}{ 4-bays } & 2-storeys & -1.5 & -0.8 & 27.2 & 13.7 & -2.9 & -0.2 & -21.2 \\
\hline & 4-storeys & -3.2 & -2.8 & -1.1 & 6.3 & -2.6 & 1.1 & 1.2 \\
\hline & 6-storeys & -4.0 & -3.6 & -10.6 & 2.0 & -2.0 & -0.1 & 12.0 \\
\hline & 8-storeys & -5.8 & -6.0 & -30.6 & -14.0 & -5.9 & 0.6 & 44.4 \\
\hline & 10 -storeys & -4.6 & -5.2 & -24.8 & -17.0 & 20.4 & 16.8 & 33.1 \\
\hline \multicolumn{2}{|c|}{ Mean error } & -3.1 & -2.7 & 1.6 & 5.6 & -2.7 & 0.6 & \\
\hline
\end{tabular}


a) Hierarchy of strength

$\bigcirc$ Member causing Yielding $\bigcirc$ Member causing ULS
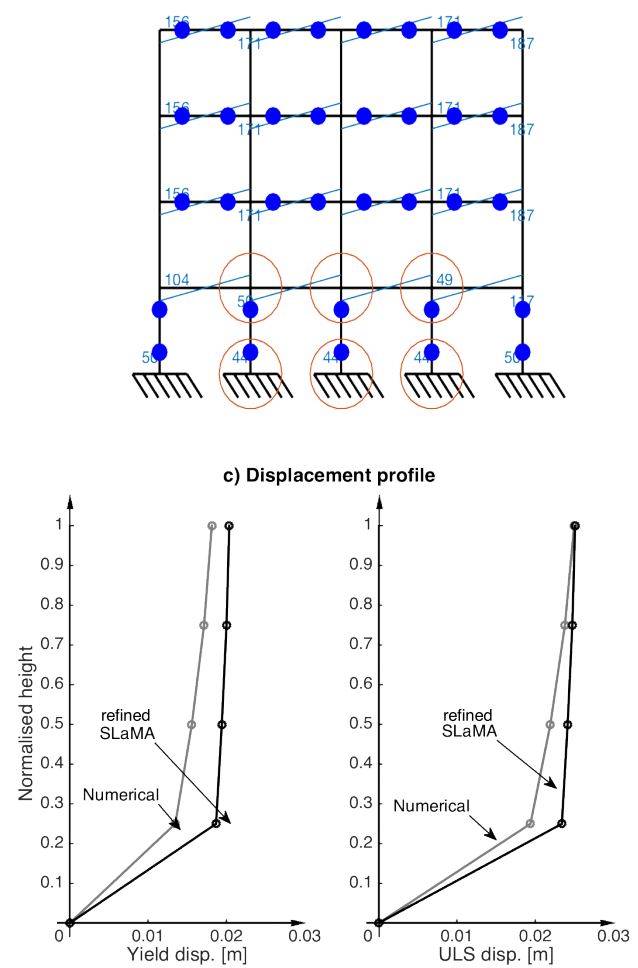

b) Plastic mechainsm at ULS

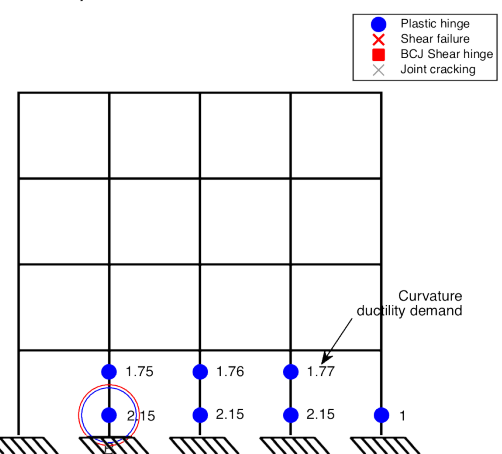

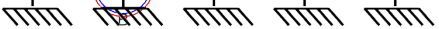

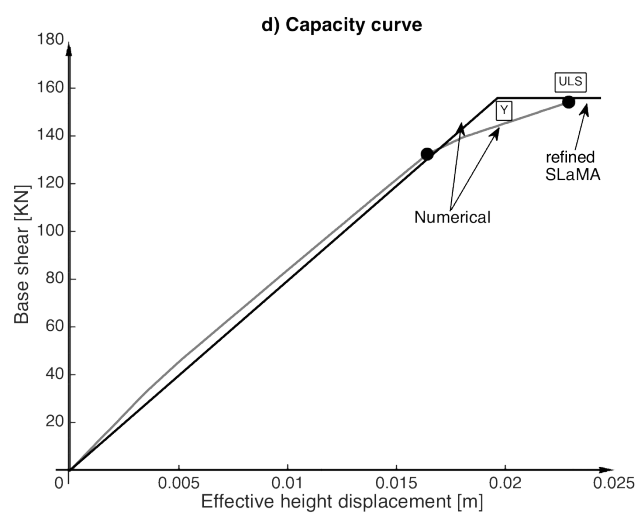

Figure 15 CSgf 4-bays, 4-storeys: summary of the results.
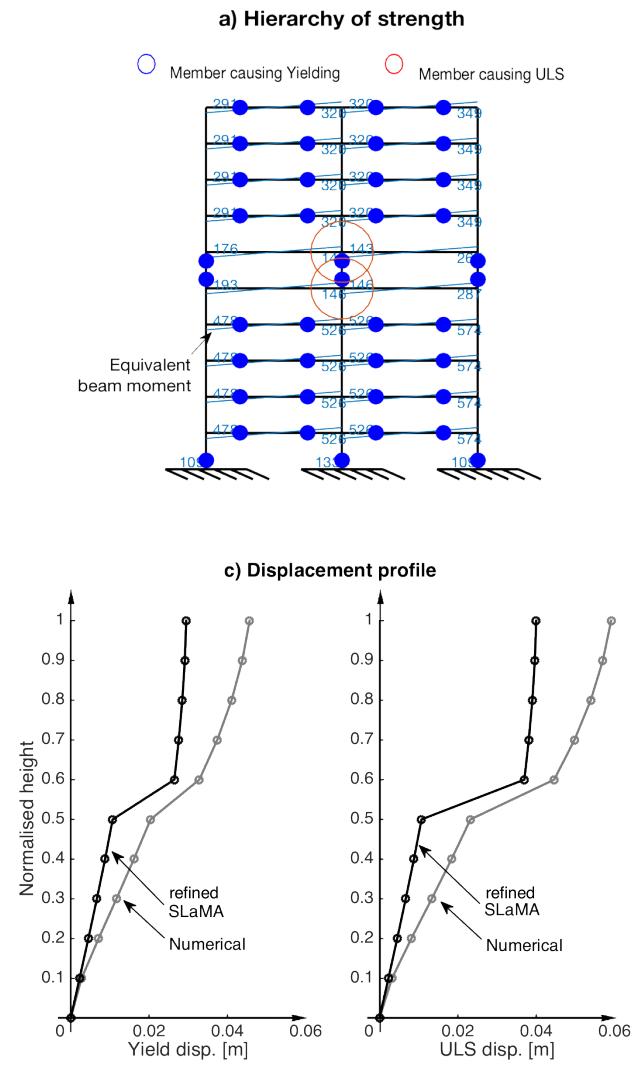

b) Plastic mechanism at ULS
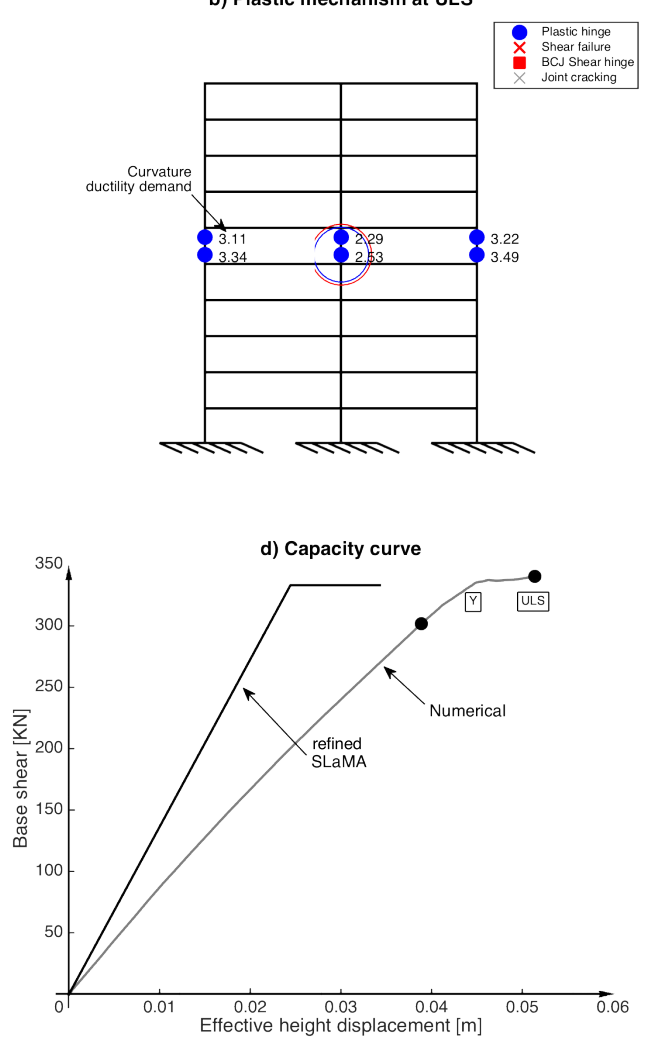
Figure 16 CSmh 2-bays, 10-storeys: summary of the results.

Table 7 CSmh sub-set SLaMA vs numerical error [\%].

\begin{tabular}{|c|c|c|c|c|c|c|c|c|}
\hline CASE & & $\operatorname{Err}\left(\mathrm{H}_{\mathrm{eff}, \mathrm{y}}\right)$ & $\operatorname{Err}\left(\mathrm{H}_{\mathrm{eff}, \mathrm{y}}\right)$ & $\operatorname{Err}\left(\delta_{\mathrm{y}}\right)$ & $\operatorname{Err}\left(\delta_{\mathrm{u}}\right)$ & $\operatorname{Err}\left(\mathrm{V}_{\mathrm{By}}\right)$ & $\operatorname{Err}\left(\mathrm{V}_{\mathrm{Bu}}\right)$ & $\operatorname{Err}\left(\mathrm{K}_{\mathrm{y}}\right)$ \\
\hline \multirow[t]{5}{*}{ 2-bays } & 2-storeys & 3.2 & 1.0 & 21.5 & 24.5 & -3.3 & -4.9 & -17.7 \\
\hline & 4-storeys & 4.0 & 2.5 & 3.6 & 6.0 & -5.8 & -3.7 & -15.0 \\
\hline & 6-storeys & 2.4 & 2.2 & -23.3 & -3.0 & -7.5 & -3.2 & 14.8 \\
\hline & 8 -storeys & 1.2 & 2.1 & -41.8 & -24.2 & -11.0 & -2.7 & 40.6 \\
\hline & 10 -storeys & 0.6 & 1.9 & -53.2 & -33.3 & -17.7 & -2.1 & 56.3 \\
\hline \multirow[t]{5}{*}{ 4-bays } & 2 -storeys & 3.0 & 0.9 & 24.7 & 24.3 & -2.9 & -3.8 & -19.8 \\
\hline & 4-storeys & 3.6 & 2.3 & 4.9 & 7.5 & -5.3 & -2.9 & -18.5 \\
\hline & 6-storeys & 2.1 & 1.9 & -17.9 & 0.7 & -6.5 & -2.4 & 6.1 \\
\hline & 8 -storeys & 1.0 & 1.8 & -35.5 & -19.9 & -8.8 & -2.2 & 27.3 \\
\hline & 10 -storeys & 0.6 & 1.8 & -45.8 & -26.7 & -14.2 & -1.7 & 35.8 \\
\hline \multicolumn{2}{|c|}{ Mean error } & 3.1 & 1.8 & 2.3 & 10.0 & -5.2 & -3.5 & 10.9 \\
\hline
\end{tabular}

\section{Final remarks}

This work deals with the seismic assessment of the non-linear capacity of RC bare frames through the Simple Lateral Mechanism Analysis (SLaMA). The original analytical procedure proposed in the NZSEE [2017] seismic assessment guidelines is herein discussed and extensively validated through non-linear pushover analyses on frame systems, by considering potential areas of improvement or extension to be of immediate and practical use for the reader/user of the NZSEE guidelines. A revised procedure for RC frames is proposed and numerically validated.

Worth noting that this paper, developed during the preparation of the guideline document itself and further refined after its publication, represents the first extensive validation of the SLaMA 2017 version available in literature and thus can be used as a scientific background document. However, further research is needed to extend SLaMA to include infill-frame interaction and systematically validate the procedure on $3 \mathrm{D}$, torsion-prone buildings.

Both the original and the refined SLaMA procedures are applied to 40 case study frames with different geometry $(2,4,6,8$ or 10 storeys, 2 or 4 bays) and expected plastic mechanisms. The database included "Beam-Sway" frames, typical of more recent "capacity-designed" structures, “Column-Sway" frames, with a local soft-storey mechanism (either at ground or at mid-height), and "Mixed-Sway" frames, typical of under-designed structures with lack of capacity design provisions and poorly detailed joint panels susceptible to shear failure. The resulting force-displacement capacity curves are compared to refined numerical pushover analyses in order to assess the accuracy and the 
reliability of the SLaMA NZSEE 2017 and the proposed refined SLaMA. The main findings can be summarised as follows:

- The SLaMA 2017 procedure is overall proved to be an accurate and reliable tool for the seismic performance assessment of RC frames with different failure mechanisms. A set of ad-hoc equations is herein proposed for RC frames exhibiting a soft-storey mechanisms involving higherthan ground level storeys, for which the original procedure does not provide an explicit solution. Moreover, a systematic error is observed in the estimation of the effective height for different plastic mechanisms. The proposed refinements to the procedure allow to overcome the abovementioned gaps and to calculate the displacement profile of the frame;

- With reference to Beam-Sway and Mixed-Sway sub-sets, the NZSEE2017 and the refined SLaMA procedures provide similar results and reasonable biases in terms of ultimate displacement $(-20 \%, 20 \%)$. On the other hand, the proposed refinements allow to considerably reduce the error for frames exhibiting a Column-Sway mechanism at the ground storey;

- In the refined procedure, the base shear at ULS is predicted with less than $10 \%$ error for the majority of the cases, compared to $20 \%$ average for the SLaMA 2017 . It is deemed that such an improvement is due to the increased accuracy in the prediction of the effective height, with errors ranging between the $0.1 \%$ and $7.4 \%$;

- The refined SLaMA still shows a relatively high dispersion $[-30 \%,+75 \%]$ in the estimation of the yield displacement. Based on the observed error trends, further research is needed to improve the prediction of this parameter, especially at sub-assembly level. Nevertheless, the observed error on the yield base shear (due to the adopted elastic-perfectly plastic assumption in SLaMA) counterbalances the error on the yield displacement in the estimation of the initial stiffness. Regarding such a parameter, the refinements to the SLaMA procedure allow to narrow the error bandwidth, which goes from $[-60 \%,+60 \%]$ for SLaMA 2017 to $[-40 \%,+20 \%]$ for the refined SLaMA. 
Based on the results of this work, it is deemed that the refined SLaMA procedure is a reliable method for the seismic assessment of frames with a maximum of 10 storeys, which restricts to 6 storeys if a Column-Sway mechanism is predicted.

\section{Acknowledgements}

This study was performed in the framework of the "SAFER Concrete Technology" and

"Advancements in Engineering Guidelines and Standards" projects, funded by the New Zealand Natural Hazard Research Platform (NHRP) and of the PE 2014-2018 joint program DPC (Italian Department of Civil Protection) - ReLUIS (Laboratories University Network of Seismic Engineering).

\section{References}

ATC 40, 1996. Applied Technology Council, Seismic evaluation and retrofit of concrete buildings, Redwood City.

Berry, M.P. \& Eberhard, M.O., 2005. Practical Performance Model for Bar Buckling. Journal of Structural Engineering, 131, pp.1060-1070.

Borzi, B., Pinho, R. \& Crowley, H., 2008. Simplified pushover-based vulnerability analysis for large-scale assessment of RC buildings. Engineering Structures, 30, pp.804-820.

Calvi, G.M., Magenes, G. \& Pampanin, S., 2002. Relevance of Beam-Column Joint Damage and Collapse in RC Frame Assessment. Journal of Earthquake Engineering, 6(1), pp.75-100.

Cardone D., Flora A., 2017 Multiple inelastic mechanisms analysis (MIMA): A simplified method for the estimation of the seismic response of RC frame buildings. Engineering Structures, 145(15), pp. 368-380.

Carr, A.J., 2016. RUAUMOKO2D - The Maori God of Volcanoes and Earthquakes. Inelastic Analysis Finite Element program. Christchurch, New Zealand.

Crowley, H., Pinho, R. \& Bommer, J., 2004. A Probabilistic Displacement-based Vulnerability Assessment Procedure for Earthquake Loss Estimation. Bulletin of Earthquake Engineering, 2(2), pp. 173-219.

Del Vecchio, C. et al., 2016. Modelling beam-column joints and FRP strengthening in the seismic performance assessment of RC existing frames. Composite Structures, 142, pp.107-116.

Del Vecchio, C., Gentile, R. \& Pampanin, S., 2017a. The Simple Lateral Mechanism Analysis (SLaMA) for the seismic performance assessment of a case study building damaged in the 
2011 Christchurch earthquake, Research report N. 2016-02, University of Canterbury, Christchurch, New Zealand.

Del Vecchio C, Del Zoppo M, Di Ludovico M, Verderame, G.M., Prota, A., 2017c. Comparison of available shear strength models for non-conforming reinforced concrete columns. Engineering Structures 148:312-327.

Del Vecchio, C., Di Ludovico, M., Balsamo, A., Prota, A., 2018a. Seismic retrofit of real beamcolumn joints using Fiber Reinforced Cement (FRC) composites. ASCE journal of Structural Engineering. 144(5).

Del Vecchio, C., Gentile, R., Di Ludovico, M., Uva, G., Pampanin, S., 2018b. Implementation and validation of the Simple Lateral Mechanism Analysis (SLaMA) for the seismic performance assessment of a damaged case study building. Journal of Earthquake Engineering, in press.

Elwood, K. J., and Moehle, J. P., 2005. Axial capacity model for shear-damaged columns. $A C I$ Structural Journal, Vol. 102(4): 578-587.

FEMA (2009). Quantification of Building Seismic Performance Factors, FEMA P695, Federal Emergency Management Agency, Washington D.C., USA. 421 p.

Gentile, R., 2017. Extension, refinement and validation of the Simple Lateral Mechanism Analysis (SLaMA) for the seismic assessment of RC structures. PhD thesis, Department of Civil, Environmental and Landscape, Building Engineering and Chemistry, Polytechnic University of Bari, Bari, Italy.

Gentile, R., Del Vecchio, C. \& Pampanin, S., 2017a. Seismic assessment of a RC case study building using the Simple Lateral Mechanism Analysis, SLaMA, method. In 6th ECCOMAS Thematic Conference on Computational Methods in Structural Dynamics and Earthquake Engineering. Rhodes Island, Greece, 15-17 June 2017.

Gentile, R., Fondi, L. \& Pampanin, S., 2017b. Vulnerabilità sismica di classi di edifici a telaio in C.A.: sensibilità della probabilità di superamento dello SLV ai dettagli costruttivi e ai materiali adottati (in Italian). In XVII Convegno 'L 'ingegneria Sismica in Italia' (ANIDIS). Pistoia, Italy.

King, D.J., Priestley, M.J.N. \& Park, R., 1986. Computer programs for concrete column design, Research Report 86/12, Department of Civil Engineering.

Kowalsky, M.J. \& Priestley, M.J.N., 2000. Improved analytical model for shear strength of circular reinforced concrete columns in seismic regions. ACI Structural Journal, 97, pp.388-396.

Magenes, G. \& Pampanin, S., 2004. Seismic response of gravity-load design frames with masonry infills. In 13th World Conference on Earthquake Engineering.

Mander, J.B., Priestley, M.J.N. \& Park, R., 1988. Theoretical stress strain model for confined concrete. Journal of Structural Engineering, 114(8), pp.1804-1826.

Montejo, L.A. \& Kowalsky, M.J., 2007. Set of codes for the analysis of reinforced concrete members, Raleigh, North Carolina. 
NTC08, 2008. DM 14 gennaio 2008 in materia di 'norme tecniche per le costruzioni'. Gazzetta ufficiale n.29 del 4 febbraio 2008. Ministero delle Infrastrutture e dei trasporti, istituto Poligrafico e Zecca dello stato. Rome, Italy.

NZS1170.5, 2004. Structural design actions, Standards New Zealand, Wellington, New Zealand.

NZS 1900, 1965. Model building bylaw: Basic design loads and commentary, NZS 1900. Standards Association of New Zealand, Wellington, NZ.

NZS3101, 2006. Part 1: Concrete structures standard - The design of concrete structures. Wellington, New Zealand.

NZSEE, 2006. New Zealand Society for Earthquake Engineering, Assessment and improvement of the structural performance of buildings in earthquakes. Wellington, New Zealand.

NZSEE, 2017. New Zealand Society for Earthquake Engineering, The seismic assessment of existing buildings - technical guidelines for engineering assessments. Wellington, New Zealand.

Pampanin, S., Akguzel, U. \& Attanasi, G., 2007. Seismic upgrading of 3-D exterior R.C. beam column joints subjected to bi-directional cyclic loading using GFRP composites. The 8th International Symposium on Fiber Reinforced Polymer Reinforcement for Concrete Structures, pp.1-10.

Pampanin, S., Calvi, G.M., Moratti, M., 2002. Seismic behaviour of RC beam-column joints designed for gravity loads. 12th European Conference on Earthquake Engineering. Paper 726.

Pampanin, S., G. Magenes, and A. Carr. 2003. Modelling of Shear Hinge Mechanism in Poorly Detailed RC Beam-Column Joints. fib Symposium 2003: "Concrete Structures in Seismic Regions”, May 2003. pp. 126-127.

Pampanin, S., Bolognini, D., and Pavese, A., 2007. "Performance-Based Seismic Retrofit Strategy for Existing Reinforced Concrete Frame Systems Using Fiber-Reinforced Polymer Composites", Journal of Composites for Construction, 11(2), pp. 211-226.

Pampanin, S., Kam, W. Y., Akguzel, U., Tasligedik, A. S., Quintana Gallo, P., 2012. Seismic Performance of Reinforced Concrete Buildings in the Christchurch CBD in 22 February 2011 Earthquake Part I: Overview, University of Canterbury, Christchurch, New Zealand.

Priestley, M. \& Calvi, G., 1991. Towards a capacity-design assessment procedure for reinforced concrete frames. Earthquake Spectra, 7(3), pp.413-437.

Priestley, M., 1997. Displacement-based seismic assessment of reinforced concrete buildings. Journal of Earthquake Engineering, 1(1), pp.157-192.

Priestley, M., Seible, F. \& Calvi, G.M., 1996. Seismic design and retrofit of bridges, New York, USA: John Wiley and Sons.

Priestley, M.J.N., Calvi, G.M. \& Kowalsky, M.J., 2007. Displacement-based seismic design of structures, IUSS Press, Pavia, Italy. 
Quintana Gallo, P., 2014. The nonlinear dynamics involved in the seismic assessment and retrofit of reinforcement concrete buildings. PhD thesis, Department of Civil and Natural Resource Engineering, University of Canterbury.

Sharpe, R.D., 1976. The Seismic Response of Inelastic Structures. PhD thesis, Department of Civil Engineering, University of Canterbury, Christchurch, New Zealand.

Smith, B.S., 1966. Behavior of square infilled frames. Journal of Structural Division, 92(1), pp.381-403. 